\title{
Cloud climatologies from the infrared sounders AIRS and IASI: strengths and applications
}

\author{
Claudia J. Stubenrauch ${ }^{1,2}$, Artem G. Feofilov ${ }^{1,2}$, Sofia E. Protopapadaki ${ }^{1,2}$, and Raymond Armante ${ }^{2}$ \\ ${ }^{1}$ Laboratoire de Météorologie Dynamique/Institute Pierre-Simon Laplace, (LMD/IPSL), CNRS, Sorbonne Universities, \\ University Pierre and Marie Curie (UPMC) Paris, University of Paris 06, Paris, France \\ ${ }^{2}$ Laboratoire de Météorologie Dynamique/Institute Pierre-Simon Laplace, (LMD/IPSL), CNRS, Ecole Polytechnique, \\ Université Paris-Saclay, Palaiseau, France
}

Correspondence to: Claudia J. Stubenrauch (stubenrauch@1md.polytechnique.fr)

Received: 4 May 2017 - Discussion started: 14 June 2017

Revised: 19 September 2017 - Accepted: 5 October 2017 - Published: 15 November 2017

\begin{abstract}
Global cloud climatologies have been built from 13 years of Atmospheric Infrared Sounder (AIRS) and 8 years of Infrared Atmospheric Sounding Interferometer (IASI) observations, using an updated Clouds from Infrared Sounders (CIRS) retrieval. The CIRS software can handle any infrared (IR) sounder data. Compared to the original retrieval, it uses improved radiative transfer modelling, accounts for atmospheric spectral transmissivity changes associated with $\mathrm{CO}_{2}$ concentration and incorporates the latest ancillary data (atmospheric profiles, surface temperature and emissivities). The global cloud amount is estimated to be $0.67-0.70$, for clouds with IR optical depth larger than about 0.1 . The spread of 0.03 is associated with ancillary data. Cloud amount is partitioned into about $40 \%$ high-level clouds, $40 \%$ low-level clouds and $20 \%$ mid-level clouds. The latter two categories are only detected in the absence of upper clouds. The A-Train active instruments, lidar and radar of the CALIPSO and CloudSat missions, provide a unique opportunity to evaluate the retrieved AIRS cloud properties. CIRS cloud height can be approximated either by the mean layer height (for optically thin clouds) or by the mean between cloud top and the height at which the cloud reaches opacity. This is valid for high-level as well as for low-level clouds identified by CIRS. IR sounders are particularly advantageous to retrieve upper-tropospheric cloud properties, with a reliable cirrus identification, day and night. These clouds are most abundant in the tropics, where high opaque clouds make up $7.5 \%$, thick cirrus $27.5 \%$ and thin cirrus about $21.5 \%$ of all clouds. The $5 \%$ annual mean excess in high-level cloud amount in the Northern compared to the
\end{abstract}

Southern Hemisphere has a pronounced seasonal cycle with a maximum of $25 \%$ in boreal summer, in accordance with the moving of the ITCZ peak latitude, with annual mean of $4^{\circ} \mathrm{N}$, to a maximum of $12^{\circ} \mathrm{N}$. This suggests that this excess is mainly determined by the position of the ITCZ. Considering interannual variability, tropical cirrus are more frequent relative to all clouds when the global (or tropical) mean surface gets warmer. Changes in relative amount of tropical high opaque and thin cirrus with respect to mean surface temperature show different geographical patterns, suggesting that their response to climate change might differ.

\section{Introduction}

Clouds cover about $70 \%$ of the Earth's surface and play a key role in the energy and water cycle of our planet. The Global Energy and Water Exchanges (GEWEX) Cloud Assessment (Stubenrauch et al., 2013) has highlighted the value of cloud properties derived from space observations for climate studies and model evaluation and has identified reasons for discrepancies in the retrieval of specific scenes, in particular thin cirrus, alone or with underlying low-level clouds. Compared to other passive remote sensing instruments, the high spectral resolution of infrared (IR) vertical sounders leads to especially reliable properties of cirrus, with IR optical depth as low as 0.1 , day and night. Channels varying in $\mathrm{CO}_{2}$ absorption are used to determine height and emissivity of a single cloud layer, which corresponds to the uppermost cloud layer in the case of multiple cloud layers. While measured radi- 
ances near the centre of the $\mathrm{CO}_{2}$ absorption band are only sensitive to the upper atmosphere, radiances from the wing of the band are emitted from successively lower levels in the atmosphere.

Spaceborne IR sounders have been observing our planet since the 1980s: the High-Resolution Infrared Radiation Sounders (HIRS) aboard the National Oceanic and Atmospheric Administration (NOAA) polar satellites provide data since 1979, the Atmospheric InfraRed Sounder (AIRS) aboard the National Aeronautics and Space Administration (NASA) Earth Observation Satellite Aqua since 2002, the Infrared Atmospheric Sounding Interferometer (IASI) aboard the European Organisation for the Exploitation of Meteorological Satellites (EUMETSAT) Meteorological Operation (Metop) since 2006 and the Cross-track Infrared Sounder (CrIS) aboard the Suomi National Polar-orbiting Partnership (NPP) satellite since 2011. A next generation of IR sounders (IASI-NG) is foreseen as part of the EUMETSAT Polar System - Second Generation (EPS-SG) program for 2021 (Crevoisier et al., 2014).

Active sensors are part of the A-Train satellite formation (Stephens et al., 2002), synchronous with Aqua, since 2006: the CALIPSO lidar and CloudSat radar, together, are capable of observing the cloud vertical structure (e.g. Henderson et al., 2013; Mace and Zhang, 2014). Whereas the lidar can detect subvisible cirrus, its beam can only penetrate the cloud down to optical depth of about 3 to 5 (in visible range). For optically thicker clouds, the radar provides the cloud base.

Our goal to establish a coherent long-term cloud climatology from different IR sounders has led to the evolution of the original LMD cloud retrieval method (Stubenrauch et al., 1999, 2006, 2008, 2010) towards an operational and modular cloud retrieval algorithm suite, Clouds from Infrared Sounders (CIRS; Feofilov and Stubenrauch, 2017). The CIRS retrieval has so far been applied to AIRS and IASI data as well as to HIRS data. The cloud property retrieval employs radiative transfer modelling and atmospheric and surface ancillary data (atmospheric temperature and water vapour profiles, surface temperature and surface emissivity, identification of snow and ice). Compared to the original retrieval, the CIRS retrieval applies improved radiative transfer calculations and a novel calibration method, accounting for latitudinal, seasonal and interannual atmospheric $\mathrm{CO}_{2}$ variations, which adjusts the atmospheric spectral transmissivity look-up tables.

The 6-year AIRS-LMD cloud climatology (Stubenrauch et al., 2010) participated in the GEWEX Cloud Assessment. In this article, we present the results of (i) an updated and extended 13-year AIRS cloud climatology (2003-2015), using two different sets of the latest ancillary data (originating from retrievals and from meteorological reanalyses), and (ii) a new 8-year IASI cloud climatology (2008-2015). After the description of data and methods in Sect. 2, Sect. 3 is dedicated to the evaluation of cloud detection and cloud height using the unique A-Train synergy of synchronous passive and active measurements. Section 4 presents average cloud properties and their regional, seasonal, interannual and longterm variability, in comparison with other data sets, as well as uncertainty estimates with respect to the used ancillary data. Section 5 concentrates on the variability of the uppertropospheric (UT) clouds with respect to changes in atmospheric conditions in order to illustrate how these data may be used for climate studies. Conclusions and an outlook are given in Sect. 6.

\section{Data and methods}

\subsection{AIRS data}

The AIRS instrument (Chahine et al., 2006) provides very high-spectral-resolution measurements of Earth-emitted radiation in 2378 spectral bands in the thermal infrared (3.74$15.40 \mu \mathrm{m})$. The spatial resolution of these measurements varies from $13.5 \mathrm{~km} \times 13.5 \mathrm{~km}$ at nadir to $41 \mathrm{~km} \times 21 \mathrm{~km}$ at the scan extremes. The polar-orbiting Aqua satellite provides observations at 01:30 and 13:30 LT (local Equator crossing time). Nine AIRS measurements $(3 \times 3)$ correspond to one footprint of the Advanced Microwave Sounder Unit (AMSU), grouped as a "golf ball".

The CIRS cloud retrieval uses measured radiances along the wing of the $15 \mu \mathrm{m} \mathrm{CO} \mathrm{CO}_{2}$ absorption band. We have chosen AIRS channels closely corresponding to the five channels used in the TIROS-N Operational Vertical Sounder (TOVS) Path-B cloud retrieval, at wavelengths of 14.19, 14.00, 13.93, 13.28 and $10.90 \mu \mathrm{m}$, and three additional channels at 14.30 , 14.09 and $13.24 \mu \mathrm{m}$ (with peaks in the weighting function at $285,415,565,755 \mathrm{hPa}$ and surface as well as at 235 , 375 and $855 \mathrm{hPa}$, respectively). The multi-spectral cloud detection, based on the spectral coherence of retrieved cloud emissivities, decides whether the AIRS footprint is cloudy (Sect. 2.5.3). For the latter, radiances in the atmospheric window between 9 and $12 \mu \mathrm{m}$ are used, at six wavelengths of $11.85,10.90,10.69,10.40,10.16$ and $9.12 \mu \mathrm{m}$.

Ancillary data necessary for the cloud retrieval, which include atmospheric temperature and water vapour profiles as well as surface skin temperature, are provided by the NASA Science Team L2 standard products (version 6 (V6); AIRS Science Team/Texeira, 2013). They were retrieved from cloud-cleared AIRS radiances within each AMSU footprint. The methodology remains essentially the same as described in Susskind et al. (2003). Compared to version 5 (V5), the most significant changes are as follows: (i) V6 uses an IR-microwave neural network solution (Blackwell et al., 2014) as a first guess for the retrieval of atmospheric temperature and water vapour profiles as well as for surface skin temperature, instead of the previously used regression approach (Susskind et al., 2014). This leads to physical solutions for many more cases than in V5. (ii) The retrieval of surface skin temperature only uses shortwave IR window chan- 
nels (Susskind et al., 2014). These modifications resulted in significant improvement of accurate temperature profiles and surface skin temperatures under partially cloudy conditions (Van T. Dang et al., 2012): Compared to V5, the surface skin temperature is larger over land in the afternoon (especially over desert) and over maritime stratocumulus regions.

In addition, we use the microwave identification of snowor ice-covered surfaces, also provided by the NASA L2 data.

Since the retrieved cloud pressure should be within the troposphere/lower stratosphere, we have determined the tropopause pressure from the atmospheric profiles, using the concept described in Reichler et al. (2003) and in Feofilov and Stubenrauch (2017). The CIRS cloud retrieval allows cloud levels up to $30 \mathrm{hPa}$ above the tropopause.

\subsection{IASI data}

IASI, developed by CNES in collaboration with EUMETSAT, is a Fourier transform spectrometer based on a Michelson interferometer, which covers the IR spectral domain from 3.62 to $15.5 \mu \mathrm{m}$. As a cross-track scanner, the swath corresponds to 30 ground fields per scan, and each of these measures a $2 \times 2$ array of footprints. The latter have a $12 \mathrm{~km}$ diameter at nadir. IASI raw measurements are interferograms that are processed to radiometrically calibrated spectra on board the satellite. Two instruments were launched so far on board the European platforms Metop-A and Metop-B, with measurements in October 2006 and September 2012, respectively, at 09:30 and 21:30 LT (Metop-A) and 10:30 and 22:30 LT (Metop-B). IASI has been providing water vapour and temperature sounding profiles for operational meteorology (accuracy requirements of, respectively, $1 \mathrm{~K}$ and $10 \%$ in the troposphere) as well as trace gas concentrations and surface and atmospheric properties, including those of aerosols and clouds (Hilton et al., 2012). For the cloud retrieval, we use radiances at the wavelengths $14.30,14.20,14.06,14.00$, $13.93,13.40,13.24$ and $10.90 \mu \mathrm{m}$ and for the multi-spectral cloud detection the radiances at 11.85, 10.90, 10.70, 10.41, 10.16 and $9.13 \mu \mathrm{m}$.

At the time we started incorporating IASI data to the CIRS cloud retrieval, two data sets of IASI-retrieved atmospheric profiles and surface temperature were available: one provided by EUMETSAT (version 5) and one by NOAA. EUMETSAT L2 temperature and water vapour version 5 products were only available for clear and partly cloudy scenes, leaving atmospheric and surface retrievals in only $9 \%$ of all cases. Therefore we first used IASI L2 ancillary data provided by NOAA. The comparison with collocated temperature profiles of the Analyzed RadioSoundings Archive (ARSA, available at the French data centre AERIS) has shown that, while AIRS-NASA and ERA-Interim (Sect. 2.3) temperature profiles do agree in general with the ARSA profiles within $1 \mathrm{~K}$, differences between IASI-NOAA and ARSA profiles were often larger than $1 \mathrm{~K}$ in the lower troposphere (not shown). In addition, a study of the influence of the dif- ferent ancillary data on the CIRS cloud amount (CA) has demonstrated that the amount of low-level clouds over ocean was underestimated when using those deduced from IASINOAA (Feofilov et al., 2015a). This might be explained by an underestimation of the sea surface temperature (SST) linked to cloud contamination. From this we concluded that the AIRS-IASI synergy to explore cloud diurnal variability in a coherent way needs ancillary data from similar retrievals or from the same source. Thus we also implemented ancillary data from the European Centre for Medium-Range Weather Forecasts (ECMWF) meteorological reanalyses into the CIRS cloud retrieval.

\subsection{ERA-Interim meteorological reanalyses}

ECMWF provides the meteorological reanalyses ERAInterim, covering the period from 1989 onwards. Dee et al. (2011) give a detailed description of the model approach and the assimilation of data. The data assimilation scheme is sequential: at each time step, it assimilates available observations to constrain the model, which then provides a short-range forecast for the next assimilation time step. Gridded data products (at a spatial resolution of $0.75^{\circ}$ latitude $\times 0.75^{\circ}$ longitude) include 6-hourly surface temperature, atmospheric temperature and water vapour profiles, as well as dynamical parameters such as horizontal and vertical large-scale winds. These data are given at universal time of 00:00, 06:00, 12:00 and 18:00. To match these data with the AIRS and IASI observations, we interpolate them to the corresponding local time, using a cubic spline function, as in Aires et al. (2004).

\subsection{Collocated AIRS-CALIPSO-CloudSat data}

All satellites of the A-Train follow each other within a few minutes. We use the same collocation procedure as in $\mathrm{Fe}$ ofilov et al. (2015b): first, each AIRS footprint is collocated with NASA CALIPSO L2 cloud data averaged over $5 \mathrm{~km}$ (version 3; Winker et al., 2009) in such a way that for each AIRS golf ball, three CALIPSO samples are matched to the centres of three AIRS footprints. These data are then collocated with the NASA L2 CloudSat-lidar geometrical profiling (GEOPROF) data (version R04; Mace and Zhang, 2014). Each of these AIRS footprints thus includes cloud top and cloud base for each of the cloud layers, detected by lidar or radar, at the spatial resolution of the radar footprints $(1.4 \mathrm{~km} \times 2.3 \mathrm{~km})$ from the GEOPROF data. Cloud optical depth (COD), cloud top, $z_{\text {top }}$ and apparent cloud base (corresponding to the real cloud base or to the height at which the cloud reaches opacity), $z_{\text {app base, }}$ are given at the spatial resolution of the CALIPSO cloud data $(5 \mathrm{~km} \times 0.09 \mathrm{~km})$. A cloud feature flag indicates whether the cloud is opaque. The CALIPSO cloud data also indicate at which horizontal averaging along the track the cloud was detected $(1,5$ or $20 \mathrm{~km}$ ), which is a measure of the COD. As in Stubenrauch 
et al. (2010), for a direct comparison with AIRS cloud data, we use clouds detected at horizontal averaging over $5 \mathrm{~km}$ or less. This corresponds to clouds with visible COD larger than about 0.05 to 0.1 (Winker et al., 2008).

The scene type of an AIRS footprint is estimated as cloudy when the CALIPSO sample as well as the GEOPROF sample include at least one cloud layer. Clear sky is defined by cloud-free CALIPSO and GEOPROF samples within the AIRS footprint.

For the evaluation of cloud height, we identify the GEOPROF cloud layer which is closest to $z_{\text {cld }}$ from AIRS and estimate the height at which the cloud reaches a COD of 0.5, $z_{\mathrm{COD} 0.5}$, from CALIPSO. $z_{\mathrm{COD} 0.5}$ is required to be located within the corresponding GEOPROF cloud layer. $z_{\mathrm{COD} 0.5}$ is deduced from the CALIPSO L2 COD, assuming a constant increase of COD from cloud top towards cloud base, except for high-level clouds, for which the shape of the ice water content profile as a function of cloud emissivity is taken into account (Feofilov et al., 2015b). As the COD of CALIPSO might be slightly underestimated (Lamquin et al., 2008), especially for larger COD, we reduce the ratio $0.5 / \mathrm{COD}$ to $0.4 / \mathrm{COD}$, used in the estimation of $z_{\mathrm{COD} 0.5}$.

\subsection{CIRS cloud property retrieval}

The cloud property retrieval is based on a weighted $\chi^{2}$ method using channels along the wing of the $15 \mu \mathrm{m} \mathrm{CO}_{2} \mathrm{ab}-$ sorption band (Stubenrauch et al., 1999). Cloud pressure and effective emissivity are determined by minimizing $\chi^{2}\left(p_{k}\right)$, computed at different atmospheric pressure levels by summation over $N$ wavelengths $\lambda_{i}$ :

$$
\begin{aligned}
\chi^{2}\left(p_{k}\right) & =\sum_{i=1}^{N}\left[\left(I_{\mathrm{cld}}\left(p_{k}, \lambda_{i}\right)-I_{\mathrm{clr}}\left(\lambda_{i}\right)\right) \cdot \varepsilon_{\mathrm{cld}}\left(p_{k}\right)\right. \\
& \left.-\left(I_{\mathrm{m}}\left(\lambda_{i}\right)-I_{\mathrm{clr}}\left(\lambda_{i}\right)\right)\right]^{2^{*}} W^{2}\left(p_{k}, \lambda_{i}\right) .
\end{aligned}
$$

$I_{\mathrm{m}}$ corresponds to the measured radiance. $I_{\mathrm{clr}}$ is the simulated radiance the IR sounder would measure in the case of clear sky, and $I_{\mathrm{cld}}\left(p_{k}\right)$ is the radiance emitted by a homogeneous opaque single cloud layer at pressure level $p_{k}$. $I_{\text {cld }}$ is calculated for $42 p_{k}$ levels (from 984 to $86 \mathrm{hPa}$ ) for the viewing zenith angle of the observation. A sensitivity study has shown that five (for HIRS) to eight channels (AIRS and IASI) are sufficient, as doubling the number of channels in the retrieval did not change the results.

By introducing empirical weights $W\left(p_{k}, \lambda_{i}\right)$, the method takes into account (i) the vertical contribution of the different channels, (ii) the growing uncertainty in the computation of $\varepsilon_{\text {cld }}$ with increasing $p_{k}$ and (iii) uncertainties in atmospheric profiles. These weights are determined for each of five typical air mass classes (tropical, midlatitude summer and winter, polar summer and winter) as in Stubenrauch et al. (1999) and in Feofilov and Stubenrauch (2017), using the spread of clear-sky radiances within these air mass classes. The clear-sky radiances have been simulated for each of the atmospheric profiles of these five air mass classes, using the 4A radiative transfer model (Scott and Chédin, 1981), and stored in the Thermodynamic Initial Guess Retrieval (TIGR) database (Chédin et al., 1985, 2003; Chevallier et al., 1998). Minimizing $\chi^{2}$ in Eq. (1) is equivalent to $d \chi^{2} / d \varepsilon_{\mathrm{cld}}=0$, from which one can extract $\varepsilon_{\text {cld }}$ as

$$
\begin{aligned}
& \varepsilon_{\mathrm{cld}}\left(p_{k}\right) \\
& =\frac{\sum_{i=1}^{N}\left[I_{\mathrm{m}}\left(\lambda_{i}\right)-I_{\mathrm{clr}}\left(\lambda_{i}\right)\right] \cdot\left[I_{\mathrm{cld}}\left(p_{k}, \lambda_{i}\right)-I_{\mathrm{clr}}\left(\lambda_{i}\right)\right] \cdot W^{2}\left(p_{k}, \lambda_{i}\right)}{\sum_{i=1}^{N}\left[I_{\mathrm{cld}}\left(p_{k}, \lambda_{i}\right)-I_{\mathrm{clr}}\left(\lambda_{i}\right)\right]^{2} \cdot W^{2}\left(p_{k}, \lambda_{i}\right)} .
\end{aligned}
$$

In general, the $\chi^{2}(p)$ profiles have a more pronounced minimum for high-level clouds than for low-level clouds. We stress here that for the identification of low-level clouds it is important to allow values larger than 1 for $\varepsilon_{\text {cld }}$, because at larger pressure $I_{\mathrm{clr}}$ and $I_{\mathrm{cld}}$ become very similar and their uncertainties may lead to values larger than 1 (Stubenrauch et al., 1999). Thus only pressure levels leading to $\varepsilon_{\text {cld }}>1.5$ are excluded from the solution. Typical $p_{\text {cld }}$ uncertainties have been estimated from a statistical analysis of the $\chi^{2}(p)$ profiles: they range from $30 \mathrm{hPa}$ for high-level clouds to $120 \mathrm{hPa}$ for low-level clouds, corresponding to about $1.2 \mathrm{~km}$ in altitude, $z_{\text {cld }}$.

In the case of atmospheric temperature inversions in the lower troposphere, the cloud height is moved to the inversion level, $z_{\text {inv }}$, defined as the highest level with $T\left(z_{\text {inv }}\right)>T_{\text {surf }}$. To detect these cases, the inversion strength, defined by $T\left(z_{\text {inv }}\right)-T_{\text {surf }}$, has to be larger than $2 \mathrm{~K}$. Depending on the ancillary data, these cases occur in about 7 to $15 \%$ of all cloudy cases. $\varepsilon_{\text {cld }}$ as defined in Eq. (2) does not have a physical meaning in the case of an inversion, since $I_{\text {cld }}\left(p_{\text {cld }}\right)$ will be greater than $I_{\mathrm{clr}}$. Therefore, we scale $\varepsilon_{\mathrm{cld}}$ and the spectral emissivities in accordance with the ratio $p_{\text {inv }} / p_{\text {cld }}$.

Cloud temperature, $T_{\text {cld }}$, is determined from $p_{\text {cld }}$, using the ancillary temperature profile similar to the observed situation (see Sect. 2.5.1). Cloud types are distinguished according to $p_{\text {cld }}$ and $\varepsilon_{\text {cld }}$. High-level clouds are defined by $p_{\text {cld }}<440 \mathrm{hPa}$, mid-level clouds by $440 \mathrm{hPa}<p_{\text {cld }}<680 \mathrm{hPa}$ and low-level clouds by $p_{\text {cld }}>680 \mathrm{hPa}$. High-level clouds may be further distinguished into opaque $\left(\varepsilon_{\mathrm{cld}}>0.95\right)$, cirrus $\left(0.95>\varepsilon_{\mathrm{cld}}>\right.$ $0.50)$ and thin cirrus $\left(\varepsilon_{\mathrm{cld}}<0.50\right) . p_{\text {cld }}$ is transformed to cloud altitude, $z_{\mathrm{cld}}$, using a standard hydrostatic conversion.

For the computation of $I_{\text {clr }}$ and $I_{\text {cld }}$ in Eq. (1), we need (i) surface type (ocean, land, ice/snow), surface temperature and spectral emissivities, (ii) atmospheric temperature and water vapour profiles as well as spectral transmissivity profiles for the atmospheric situation of the measurements. The latter have been calculated using the $4 \mathrm{~A}$ radiative transfer model, separately for each satellite viewing zenith angle (up to $50^{\circ}$ ) and for about 2300 representative clear-sky atmospheric temperature and humidity profiles of the TIGR database. 
In the cloud retrieval, the TIGR database is searched for the atmospheric profile corresponding best to the observational conditions by applying a proximity recognition which compares the atmospheric temperature and water vapour profiles from the ancillary data with those from TIGR as in Stubenrauch et al. (2008). The preparation and evaluation of these ancillary data is presented in Sect. 2.5.1.

\subsubsection{Preparation and comparison of atmospheric and surface ancillary data}

Spectral surface emissivities. Over land, we use monthly mean spectral surface emissivity climatological values at a spatial resolution of $0.25^{\circ} \times 0.25^{\circ}$, retrieved from IASI measurements (Paul et al., 2012). For AIRS, these spectral surface emissivities have been interpolated to the AIRS wavelengths. Over ocean, the surface emissivity is set to 0.99 for $\lambda_{i}<10 \mu \mathrm{m}$ and 0.98 for $\lambda_{i} \geq 10 \mu \mathrm{m}$ (Wu and Smith, 1997). Over snow and ice, the spectral surface emissivities are taken from Hori et al. (2006) and, as they depend on the viewing zenith angle, they had to be corrected like in Smith et al. (1996).

Atmospheric profiles and surface temperature. Since IR sounders, in combination with microwave sounders, were originally designed for the retrieval of atmospheric temperature and humidity profiles, the atmospheric clear-sky situation can then be directly described by simultaneous L2 atmospheric profiles of good quality. If good-quality data are not available for a given measurement, we use $1^{\circ}$ latitude $\times 1^{\circ}$ longitude averages of good-quality data. If still no data are available, we interpolate these averages in time (inversely proportional to distance within maximal \pm 15 days) and then in space (inversely proportional to distance within maximal $3^{\circ}$ longitude, considering the same surface type).

To define atmospheric temperature and humidity profiles as well as surface temperature of good quality, one has to find a compromise between an acceptable quality and enough statistics.

This led to the following quality criteria in the case of ancillary data from AIRS-NASA (V6):

- Surface temperature is of good quality if the provided retrieval error is smaller than $3 \mathrm{~K}$ for ocean, $6 \mathrm{~K}$ for land and $7 \mathrm{~K}$ for ice or snow, respectively. It should also be larger than $180 \mathrm{~K}$ and smaller than $400 \mathrm{~K}$.

- Atmospheric temperature profiles are of bad quality when three consecutive layers have retrieval errors larger than $2 \mathrm{~K}, 2 \mathrm{~K}$ and $2 \mathrm{~K}$ over ocean; $2.5 \mathrm{~K}, 2.5 \mathrm{~K}$ and $3 \mathrm{~K}$ over land; and $2.5 \mathrm{~K}, 2.5 \mathrm{~K}$ and $5 \mathrm{~K}$ over ice or snow, between $70 \mathrm{hPa}$ and $500 \mathrm{hPa}$, between $500 \mathrm{hPa}$ and surface, and near surface, respectively.

- For atmospheric water vapour profiles the NASA L2 quality criteria were kept (Olsen et al., 2013).
Nevertheless, the SSTs of good quality from AIRS-NASA were still slightly colder than those of ERA-Interim. As this effect is most probably linked to AIRS-NASA residual cloud contamination, we added to the AIRS-NASA SSTs the minimum between the retrieval error and $0.5 \mathrm{~K}$. Since differences over land might be positive or negative (Fig. 2), we left the AIRS-NASA surface temperature $\left(T_{\text {surf }}\right)$ values unchanged.

For ERA-Interim, the time-interpolated atmospheric profiles and surface temperatures are always available. However, we found that the time-interpolated ERA-Interim SSTs did not show a diurnal cycle, with most amplitudes less than $0.2 \mathrm{~K}$. As this is not consistent with observations (e.g. Webster et al., 1996), we applied a simple parameterized correction, linking the SST diurnal cycle to peak insolation (Webster et al., 1996). The coefficient between the SST diurnal amplitude and the maximal solar flux at given latitude, longitude, solar zenith angle and local time was adjusted to $0.005 \mathrm{~K} \mathrm{Wm}^{-2}$, so that the SST diurnal amplitude is consistent with recent observations (e.g. Seo et al., 2014). Without this correction, the CA at night and early afternoon was $78 \%$ and $71 \%$, respectively, compared to $71 \%$ and $71 \%$ when using AIRS ancillary data. The correction led to $76 \%$ and $73 \%$, respectively, closer to the results using AIRS ancillary data. Over land, without changes in $T_{\text {surf }}, \mathrm{CA}$ at night and early afternoon is $62 \%$ and $56 \%$ with ERA-Interim and $56 \%$ and $58 \%$ with AIRS-NASA, respectively.

Figure 1 presents comparisons between $T_{\text {surf }}$, as used in the cloud retrieval, deduced from AIRS-NASA and from ERAInterim and collocated surface air temperature, $T_{\text {surf }}^{\text {air }}$, from the ARSA database. One would expect that over land $T_{\text {surf }}$ would be colder than $T_{\text {surf }}^{\text {air }}$ during night and warmer than $T_{\text {surf }}^{\text {air }}$ in the afternoon; this effect should be stronger for warmer temperatures, especially if the climate is dry. SST should be similar to $T_{\text {surf }}^{\text {air }}$ in the tropics: slightly warmer in midlatitudes and colder in polar regions. The distributions in Fig. 1 reflect the expectations, with similar peak positions for AIRSNASA and ERA-Interim, although distributions over land are slightly broader for AIRS-NASA than for ERA-Interim. They are also shifted towards colder values at night. In the afternoon, $T_{\text {surf }}$ of AIRS-NASA is slightly larger than $T_{\text {surf }}$ of ERA-Interim for situations with warm $T_{\text {surf }}$ Colder AIRSNASA values might still indicate some cloud contamination, whereas the colder values of ERA-Interim over warm land in the afternoon might indicate an underestimation, especially over desert, as has already been pointed out by Trigo et al. (2015). The effect of $T_{\text {surf }}$ on CA will be further investigated in Sect. 3.1 .

\subsubsection{Accounting for changes in atmospheric $\mathrm{CO}_{2}$ concentration}

The TIGR database of atmospheric spectral transmissivities was created for an atmosphere with a fixed $\mathrm{CO}_{2}$ volume mixing ratio of 372 ppmv. However, the atmospheric $\mathrm{CO}_{2}$ concentration varies latitudinally, seasonally and with time. Both 


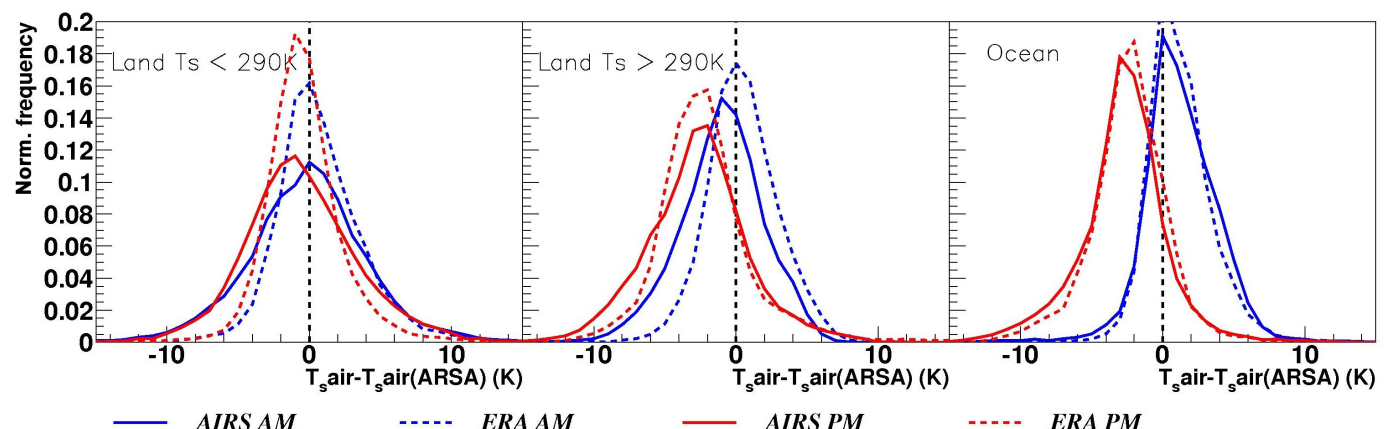

Figure 1. Normalized distributions of the difference between surface skin temperature, as used in the cloud retrieval, deduced from AIRSNASA of good quality and from ERA-Interim, and collocated surface air temperature of the ARSA database. Statistics includes January and July from 2003-2015, separately over land for colder temperatures $\left(T_{\text {surf }}<290 \mathrm{~K}\right)$, over land for warmer temperatures $\left(T_{\text {surf }}>290 \mathrm{~K}\right)$ and over ocean.

CA difference (AIRS-NASA - ERA-Interim ancillary)

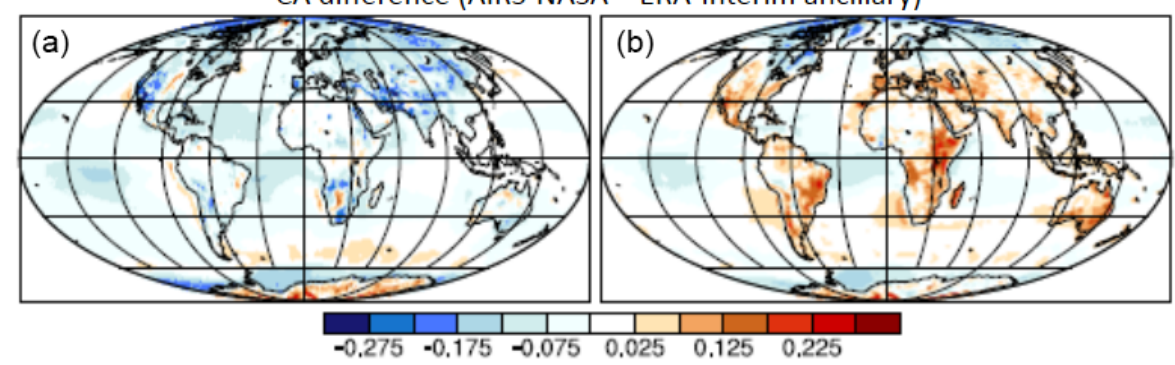

$\mathrm{T}_{\text {surf }}$ difference (AIRS-NASA - ERA-Interim ancillary)

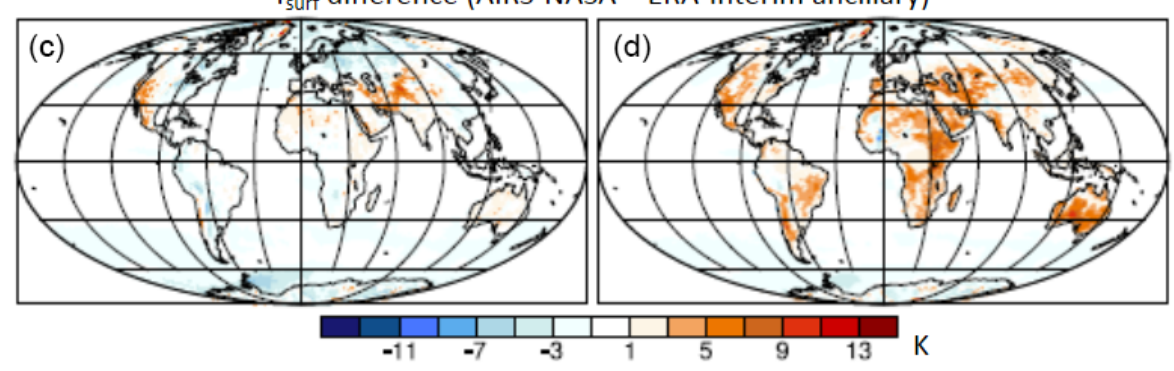

Figure 2. Geographical maps of difference in total CA $(\mathbf{a}, \mathbf{b})$ between the two AIRS-CIRS data sets, based on ancillary data from AIRSNASA and from ERA-Interim, and in $T_{\text {surf }}(\mathbf{c}, \mathbf{d})$ between AIRS-NASA and ERA-Interim as used in the retrieval, separately at 01:30 LT (a, c) and at 13:30 LT (b, d).

the increase during the last 10 years and the seasonal variability in the Northern Hemisphere (NH) are of the order of $\sim 20$ ppmv. The latter is related to the vegetation and fossil fuel burning seasonality. The difference between an averaged value and actual $\mathrm{CO}_{2}$ volume mixing ratio can easily reach $10 \%$. This is a noticeable change, as the concentration enters the power of the exponent in the calculation of the transmissivity, $\tau$. To avoid errors associated with $\mathrm{CO}_{2}$ changes in the radiative transfer computations, we rescale the transmissivity as

$\tau=\exp \left(-\beta-\alpha \cdot \mathrm{CO}_{2}{ }^{\text {current }}\right)$,

with $\alpha=-k \cdot \log \left(\tau^{\mathrm{ref}}\right) / \mathrm{CO}_{2}{ }^{\text {ref }}$ and $\beta=\alpha \cdot C O_{2}^{\text {ref }} \cdot \log (1-$ $k) / k$, where $k$ is the relative $\mathrm{CO}_{2}$ contribution to the opac- ity of the channel. Details are described in Feofilov and Stubenrauch (2017). The $\mathrm{CO}_{2}$ concentrations are taken from (GLOBALVIEW-CO2, 2013).

This correction also removes long-term biases due to increasing $\mathrm{CO}_{2}$ in the atmosphere from anthropogenic $\mathrm{CO}_{2}$ emissions, which introduced an artificial increase in the $\mathrm{CA}$ time series. Applying the correction of Eq. (3) has eliminated this bias (see Sect. 4).

\subsubsection{Multi-spectral a posteriori cloud detection}

Once the cloud properties are retrieved, to constrain cloud definition, we use the spectral standard deviation $\left(\sigma\left(\varepsilon\left(\lambda_{i}\right)\right)\right)$ of retrieved cloud emissivities between 9 and $12 \mu \mathrm{m}$, wave- 
lengths in the IR atmospheric window, as described in Stubenrauch et al. (2010). For each footprint, cloud emissivities $\varepsilon_{\text {cld }}$ are determined at six wavelengths, $\lambda_{i}$ (Sect. 2.1), as

$\varepsilon_{\mathrm{cld}}\left(\lambda_{i}\right)=\frac{I_{\mathrm{m}}\left(\lambda_{i}\right)-I_{\mathrm{clr}}\left(\lambda_{i}\right)}{I_{\mathrm{cld}}\left(p_{\mathrm{cld}}, \lambda_{i}\right)-I_{\mathrm{clr}}\left(\lambda_{i}\right)}$.

$I_{\text {cld }}$ is now determined for $p_{\text {cld }}$, retrieved by the $\chi^{2}$ method (see above).

The relative standard deviation of these cloud emissivities, $\sigma\left(\varepsilon\left(\lambda_{i}\right)\right) / \varepsilon_{\text {cld }}$, is much larger when the footprint is partly cloudy or clear (hence $p_{\text {cld }}$ is biased) than for cloudy cases, when $p_{\text {cld }}$ and $\varepsilon_{\text {cld }}$ are well determined. This behaviour is illustrated in Fig. 2 of Stubenrauch et al. (2010) and in Fig. S1 of the Supplement, contrasting distributions of the relative standard deviation of these cloud emissivities, $\sigma\left(\varepsilon\left(\lambda_{i}\right)\right) / \varepsilon_{\text {cld }}$, of cloudy and clear-sky scenes from CALIPSO samples. Guided by these figures and experimenting with thresholds to obtain a good agreement in CA compared to CALIPSOCloudSat (Sect. 3) and to other data sets (Sect. 4), we define the AIRS footprint as cloudy if the following conditions are fulfilled: $\sigma\left(\varepsilon\left(\lambda_{i}\right)\right) / \varepsilon_{\text {cld }}<0.17$ for ocean (both ancillary data), $\sigma\left(\varepsilon\left(\lambda_{i}\right)\right) / \varepsilon_{\text {cld }}<0.20$ for land (both ancillary data) and $\sigma\left(\varepsilon\left(\lambda_{i}\right)\right) / \varepsilon_{\text {cld }}<0.30 / 0.20$ (AIRS-NASA/ERA-Interim ancillary data) for ice and snow.

For IASI we do not have the possibility to distinguish $\sigma\left(\varepsilon\left(\lambda_{i}\right)\right) / \varepsilon_{\text {cld }}$ distributions according to CALIPSOCloudSat cloudy and clear-sky scenes. However, the overall distributions of $\sigma\left(\varepsilon\left(\lambda_{i}\right)\right) / \varepsilon_{\text {cld }}$ are similar for AIRS and IASI, comparing retrievals based on ERA-Interim ancillary data. Therefore we use the same thresholds for the IASI cloud detection.

To reduce misidentification of clear sky as high-level clouds, only clouds with $\varepsilon_{\text {cld }} \geq 0.10$ are considered.

\subsubsection{Summary of changes compared to the previous version of the AIRS-LMD cloud retrieval}

Compared to the retrieval used to produce the 6-year AIRSLMD cloud climatology (Stubenrauch et al., 2010), the following changes have been implemented into the CIRS algorithm:

- extension of minimum cloud pressure from 106 to $86 \mathrm{hPa}$;

- update of atmospheric and surface ancillary data from NASA V5 to NASA V6;

- improved interpolation of atmospheric and surface ancillary data;

- moving the cloud to the inversion level and scaling $\varepsilon_{\text {cld }}$ in the case of atmospheric temperature inversions;

- improved radiative transfer computations of the TIGR atmospheric spectral transmissivities;
- adjusting the TIGR spectral transmissivity for the lowermost layer in accordance with the observed surface pressure;

- decreased cloud detection thresholds due to improved radiative transfer computations;

- reducing the number of cloud detection tests to one, which is based on the coherence of cloud spectral emissivity;

- considering clouds with $\varepsilon_{\text {cld }} \geq 0.10$, instead of $\varepsilon_{\text {cld }} \geq 0.05$;

- taking into account variable $\mathrm{CO}_{2}$ concentration in spectral transmissivity estimates.

As we will see in Sect. 4, the impact of these changes is in general small, but taking into account variable $\mathrm{CO}_{2}$ concentration is important for addressing the long-term variability of clouds.

\section{Evaluation of cloud properties using the A-Train synergy}

The lidar and radar of the CALIPSO and CloudSat missions provide a unique opportunity to evaluate the retrieved AIRS cloud properties such as cloud amount and cloud height and to explore the vertical structure of the AIRS cloud types (Stubenrauch et al., 2010). These results can then be transposed to cloud types determined by the CIRS retrieval using other IR sounders.

In the following, we analyse 3 years (2007-2009) of collocated AIRS-CALIPSO-CloudSat data, separately for three latitude bands: tropical and subtropical latitudes $\left(30^{\circ} \mathrm{N}-\right.$ $\left.30^{\circ} \mathrm{S}\right)$, midlatitudes $\left(30-60^{\circ} \mathrm{N}\right.$ and $\left.30-60^{\circ} \mathrm{S}\right)$ and polar latitudes $\left(60-90^{\circ} \mathrm{N}\right.$ and 60-90 $\left.\mathrm{S}\right)$.

\subsection{Cloud detection}

The hit rates (fraction of agreeing cloudy and clear cases) between the AIRS-CIRS cloud detection and the lidar-radar cloud detection (Sect. 2.4) are $85 \%(84 \%$ ) over ocean, $82 \%$ (79\%) over land and $70 \%(73 \%)$ over ice/snow. Values in parentheses correspond to ERA-Interim ancillary data. Table 1 presents separate comparisons for the three latitude bands. In general, the hit rates are quite high, considering that CALIPSO and GEOPROF data only sample a small area of the AIRS footprints. They are slightly higher over ocean than over land. Compared to the AIRS-LMD cloud retrieval presented in Stubenrauch et al. (2010), the agreement with CALIPSO-CloudSat has improved both over ocean and land but slightly decreased over sea ice. The latter can be explained by applying only one test over all surface types. In the earlier version we used an additional brightness temperature difference test related to temperature inversions. A de- 

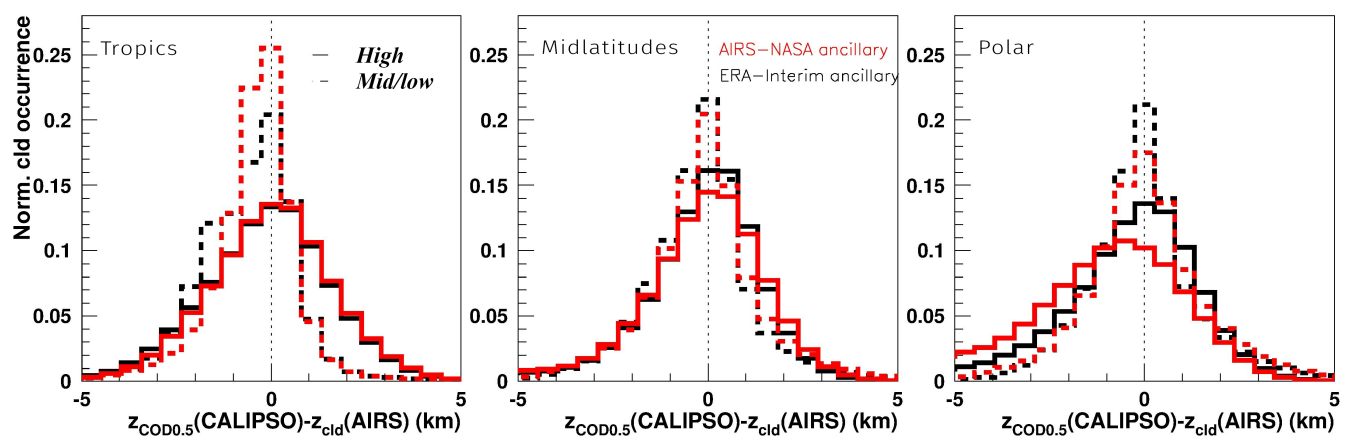

Figure 3. Normalized frequency distributions of the difference between the cloud height at which the optical depth reaches a value of 0.5 from CALIPSO and $z_{\text {cld }}$ from AIRS; $z_{\text {cld }}$ is compared to the cloud layer of CALIPSO, which corresponds to the CloudSat lidar GEOPROF, and is the closest to $z_{\text {cld }}\left(\right.$ Sect. 2.4). Analysis over tropics $\left(30^{\circ} \mathrm{N}-30^{\circ} \mathrm{S}\right)$, midlatitudes $\left(30-60^{\circ}\right)$ and polar latitudes $\left(60-85^{\circ}\right)$, separately for high-level clouds and for clouds with $p_{\text {cld }}>440 \mathrm{hPa}$. The effect of using different ancillary data is also presented. Statistics include 3 years (2007-2009) of observations at 01:30 LT.

Table 1. Hit rates between AIRS-CIRS and CALIPSO-CloudSat cloud detection. Statistics include 3-year (2007-2009) collocated observations at 01:30 LT.

\begin{tabular}{lcccccccc}
\hline \multirow{2}{*}{$\begin{array}{l}\text { Surface/latitude } \\
\text { Ancillary data }\end{array}$} & \multicolumn{2}{c}{ Tropics } & & \multicolumn{2}{c}{ Midlatitudes } & & \multicolumn{2}{c}{ Polar } \\
\cline { 2 - 3 } \cline { 8 - 9 } \cline { 8 - 9 } \cline { 8 - 9 } Ocean & AIRS & ERA & & AIRS & ERA & & AIRS & ERA \\
Land & $86.5 \%$ & $84.2 \%$ & & $90.2 \%$ & $91.5 \%$ & & $93.0 \%$ & $95.0 \%$ \\
Sea ice & $86.4 \%$ & $83.2 \%$ & & $80.7 \%$ & $77.6 \%$ & & $77.3 \%$ & $79.7 \%$ \\
Snow & & & & $71.5 \%$ & $82.0 \%$ & & $71.2 \%$ & $81.2 \%$ \\
& $73.5 \%$ & $71.9 \%$ & & $74.9 \%$ & $68.5 \%$ & & $65.5 \%$ & $66.7 \%$ \\
\hline
\end{tabular}

tailed analysis (not shown) indicated that it also introduced noise.

To further illustrate CA uncertainties linked to ancillary data, we investigate, in Fig. 2, geographical maps of differences in CA and $T_{\text {surf }}$, using ancillary data from AIRS-NASA and from ERA-Interim. With AIRS-NASA ancillary data, CA over land is often smaller during night and larger in the afternoon, with $T_{\text {surf }}$ also smaller during night and larger in the afternoon over large parts of the continents. Considering the $T_{\text {surf }}$ comparison with ARSA (Sect. 2.5), this means that over land CA is slightly underestimated during night with AIRS-NASA ancillary data, while slightly underestimated in the afternoon with ERA-Interim ancillary data. Patterns of differences in atmospheric water vapour are less reflected in those of CA (not shown), but slightly more atmospheric water vapour in the ancillary data (as in the tropics for AIRSNASA compared to ARSA and ERA-Interim) might lead to a slight underestimation of CA.

\subsection{Cloud height}

Figure 3 presents normalized distributions of the difference between $z_{\text {COD0.5 }}$ from CALIPSO (Sect. 2.4) and $z_{\text {cld }}$, from AIRS for the three latitude bands. We compare results for $p_{\text {cld }}<440 \mathrm{hPa}$ and $p_{\text {cld }} \geq 440 \mathrm{hPa}$ separately for AIRSNASA and ERA-Interim ancillary data. In general, all dis- tributions peak around $0 \mathrm{~km}$ and are slightly narrower for lower-level clouds than for high-level clouds. Results are similar for both ancillary data, with a slight cloud height overestimation of lower-level clouds over tropical ocean for ERA-Interim (not shown) and a height overestimation of some clouds over polar ocean for AIRS-NASA ancillary data (not shown). The latter can be explained by the fact that in some of these regions $T_{\text {surf }}$ and atmospheric profiles of good quality are only available $10 \%$ of the time. When comparing distributions of $z_{\text {top }}-z_{\text {cld }}$, the peaks for lower clouds are still around $0 \mathrm{~km}$, whereas for high-level clouds $z_{\text {cld }}$ lies on average $1.5 \mathrm{~km}$ below the cloud top (not shown), very similar to results in Stubenrauch et al. (2010). This means that $T_{\text {cld }}$ is about $10 \mathrm{~K}$ warmer than the cloud top (Fig. S2 of the Supplement). The broader distributions for high-level clouds compared to low-level clouds may be explained by the fact that high-level clouds often have diffuse cloud tops (e. g. Liao et al., 1995), especially in the tropics $\left(z_{\text {top }}-z_{\text {cld }}\right.$ is slightly larger for the same $\varepsilon_{\mathrm{cld}}$, as shown in Fig. 5). To summarize, $z_{\text {cld }}$ can be approximated by (i) the height of maximum lidar backscatter (Stubenrauch et al., 2010), (ii) $z_{\mathrm{COD} 0.5}$ (Fig. 3) or (iii) the mean layer height (for optically thin clouds) or the mean between cloud top and the height at which the cloud reaches opacity), as shown in Fig. S2 in the Supplement (considering mid- $\left.p_{\text {cld }}\right)$. 

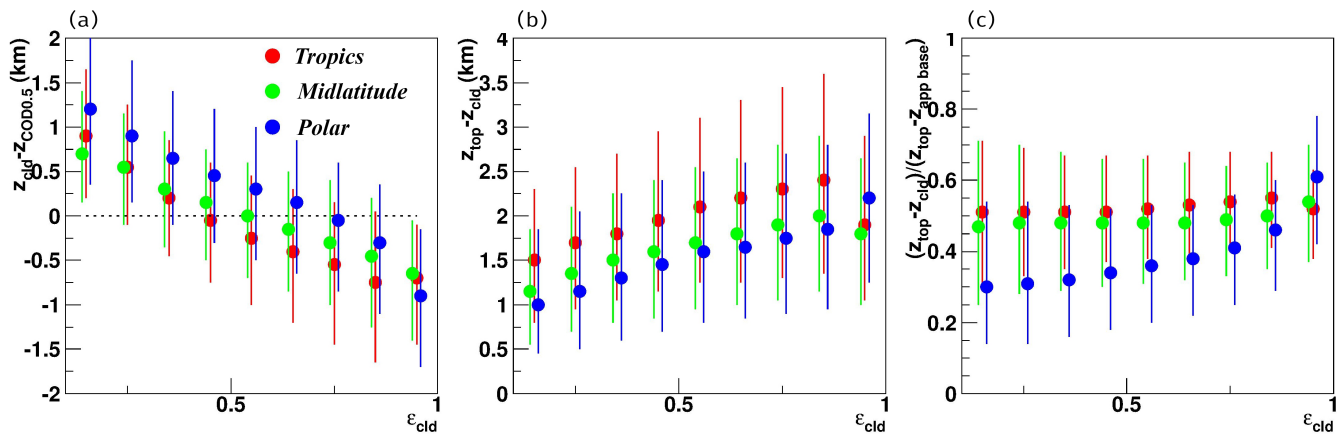

Figure 4. (a) $z_{\mathrm{cld}}-z_{\mathrm{COD} 0.5}$, (b) $z_{\text {top }}-z_{\mathrm{cld}}$ and (c) $\left(z_{\text {top }}-z_{\mathrm{cld}}\right) /\left(z_{\text {top }}-z_{\text {app base }}\right)$ as functions of $\varepsilon_{\text {cld }}$ for high-level clouds in the tropics, midlatitudes and polar latitudes. Presented are median values and the interquartile ranges. Three years of statistics, for which $z_{\mathrm{cld}}$ and $z_{\mathrm{COD} 0.5}$ lie within vertical cloud borders from GEOPROF. Observations at 01:30 LT.

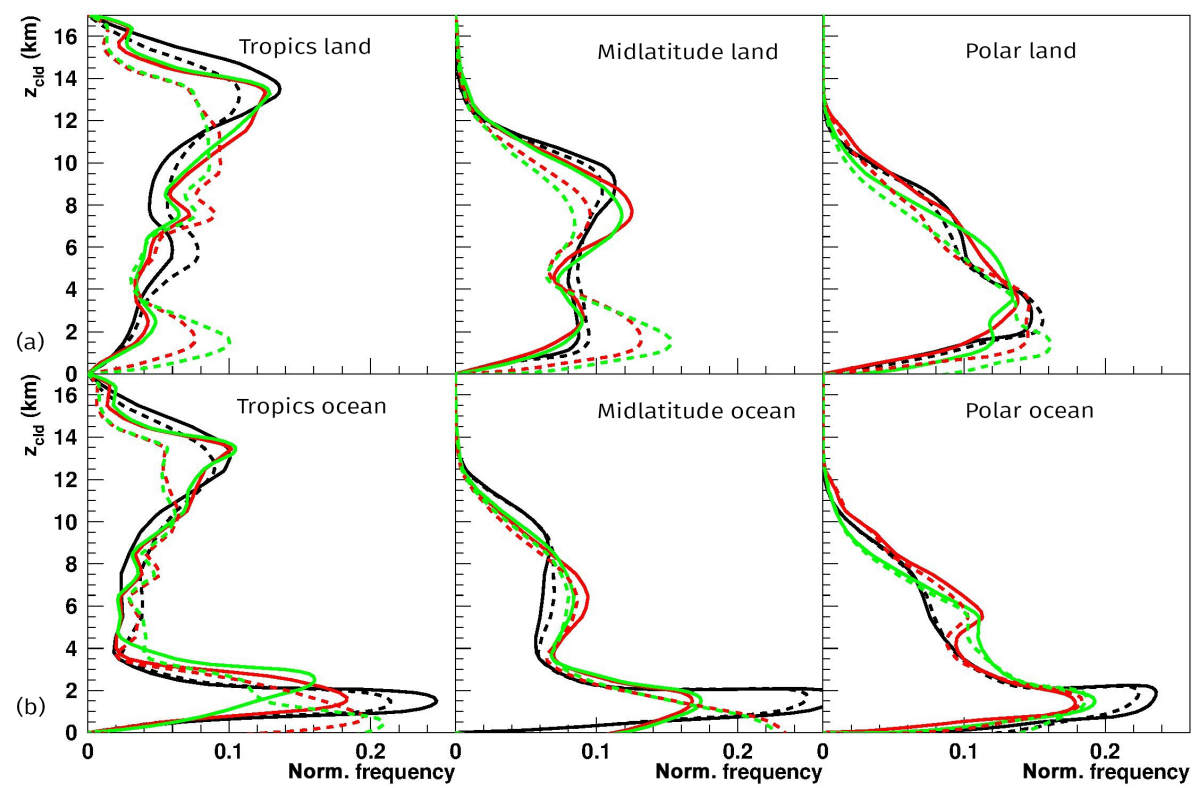

Figure 5. Normalized frequency distributions of $z_{\text {COD } 0.5}$ from CALIPSO (black) and of $z_{\text {cld }}$ from AIRS, using ancillary data from AIRSNASA (red) and from ERA-Interim (green), separately over land (a) and over ocean (b), in the tropics, midlatitudes and polar latitudes. For each data set, two distributions are compared: statistics of all detected clouds, except subvisible cirrus (dashed line), and only of single-layer clouds with a cloud coverage filling the AIRS golf ball (full line).

For a more detailed investigation of the different height approximations, Fig. 4 compares median values of $z_{\text {cld }}-$ $z_{\mathrm{COD} 0.5}, z_{\text {top }}-z_{\text {cld }}$ and $\left(z_{\text {top }}-z_{\text {cld }}\right) /\left(z_{\text {top }}-z_{\text {app base }}\right)$ as functions of $\varepsilon_{\text {cld }}$ for high-level clouds. For this analysis we have selected cases for which $z_{\text {cld }}$ lies between top and base of the closest GEOPROF cloud layer. This leaves about $82 \%$, $73 \%$ and $57 \%$ of the statistics in tropics, midlatitudes and polar regions, respectively. $z_{\mathrm{cld}}$ varies from $1 \mathrm{~km}$ above for $\varepsilon_{\mathrm{cld}}=0.1$ to $1 \mathrm{~km}$ below $z_{\mathrm{COD} 0.5}$ for $\varepsilon_{\mathrm{cld}}=1$, assuming that $z_{\mathrm{COD} 0.5}$ is accurately estimated for all $\varepsilon_{\text {cld }}$ (Sect. 2.4). In that case, $z_{\text {cld }}$ of thin cirrus should be approximated by a height with $\mathrm{COD}<0.5$ and $z_{\text {cld }}$ of opaque high clouds by a height with COD $>0.5$. In contrast, $z_{\text {cld }}$ lies about $1 \mathrm{~km}$ to $2 \mathrm{~km}$ below $z_{\text {top }}$, the difference to cloud top increasing with $\varepsilon_{\text {cld }}$ (except for $\varepsilon_{\text {cld }}$ close to 1$)$. Since $z_{\text {top }}-z_{\text {app base }}$ also increases with $\varepsilon_{\text {cld }}$ (not shown), $\left(z_{\text {top }}-z_{\text {cld }}\right) /\left(z_{\text {top }}-z_{\text {app base }}\right)$ does not depend on $\varepsilon_{\text {cld }}$ and is about 0.5 . We deduce that it probably needs less vertical extent for opaque clouds than for semi-transparent cirrus to reach a COD of 0.5 , while the $\chi^{2}$ method determines a height within the cloud, which corresponds well to the mean between cloud top and base or the height at which the cloud reaches opacity, independent of $\varepsilon_{\text {cld }}$. This is important to take into account for the determination of radiative fluxes and heating rates of UT clouds, when using CIRS cloud heights. We want to stress that $\left(z_{\text {top }}-z_{\text {cld }}\right) /\left(z_{\text {top }}-z_{\text {app base }}\right)$ is about $0.5(0.4$ to 0.6$)$ for low-level clouds as well, while $z_{\text {cld }}$ lies only about 0.1 to 
$0.4 \mathrm{~km}$ below $z_{\mathrm{COD} 0.5}$ and about $0.5 \mathrm{~km}$ below $z_{\text {top }}$ (Fig. S3 of the Supplement).

Finally, Fig. 5 presents normalized frequency distributions of $z_{\text {cld }}$, using both sets of ancillary data, and $z_{\mathrm{COD} 0.5}$, whenever clouds are detected (excluding subvisible cirrus;

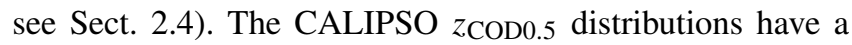
slightly larger part of high-level clouds, especially in the tropics, and the AIRS $z_{\text {cld }}$ distributions show a slightly larger part of low-level clouds over land. The latter disappear if one considers only cases with all three CALIPSO samples cloudy within an AIRS golf ball. Thus these low-level clouds are part of partly cloudy fields for which it is difficult to compare results from samples of very different spatial resolution. The distributions compare better when only mostly covered cloud fields are considered (three CALIPSO samples cloudy within an AIRS golf ball). In the tropics, the peak of the AIRS $z_{\text {cld }}$ distributions for high-level clouds is still slightly broader towards lower heights than for CALIPSO (not shown). Additional filtering, excluding multi-layer clouds, ultimately leads to very similar distributions, also presented in Fig. 5. A plausible interpretation is that in cases of multiple cloud layers with the upper cloud layer not fully covering the large AIRS footprint, instrument received radiation is mixed from different cloud layers, and thus $z_{\text {cld }}$ is slightly lower than the one of the uppermost cloud layer. The distributions in the midlatitudes still peak at slightly lower heights, because highlevel clouds in these latitudes are on average optically thicker (storm tracks) than in the tropics. In these cases $z_{\text {cld }}$ lies below $z \operatorname{COD} 0.5$, as we have seen in Fig. 4. The choice of ancillary data influences only mildly the $z_{\text {cld }}$ distributions, with a slightly larger contribution of low-level clouds over land for ERA-Interim. This difference disappears if we consider only mostly covered cloud fields, as the contribution of low-level clouds strongly decreases over land. Over ocean, the effect is much smaller. This indicates that low-level clouds over ocean appear more often as stratus decks whereas those over land appear more frequently as cumulus, as expected.

\section{Average cloud properties and variability}

In this section we give a short overview of cloud properties of the AIRS-CIRS and IASI-CIRS cloud climatologies. Monthly L3 data, gridded at a spatial resolution of $1^{\circ}$ latitude $\times 1^{\circ}$ longitude, have been produced in the same manner as for the GEWEX Cloud Assessment database (Stubenrauch et al., 2013): in a first step, cloud properties and their uncertainties, deduced from the $\chi^{2}$ method, were averaged per observation time over $1^{\circ}$ latitude $\times 1^{\circ}$ longitude; in a second step, these were averaged per month. In addition to the monthly averages, the database also includes histograms of the cloud properties.

Figure 6 compares normalized frequency distributions of $p_{\text {cld }}(\mathrm{CP})$ over $30^{\circ}$ wide latitude bands during boreal winter and boreal summer, separately over land and over ocean. As one can see, the AIRS and IASI CP distributions are very similar. Their relative contribution of high-level clouds is slightly larger over land than over ocean, especially in the tropics, while the contribution of low-level clouds is larger over ocean. Considering seasonality, the strongest signature is the shift of the Intertropical Convergence Zone (ITCZ) towards the summer hemisphere, manifested by a large amount of high-level clouds (from cirrus anvils), especially over land.

Figure 7 presents global averages of total CA and relative contributions of high-level, mid-level and low-level clouds, determined by dividing these cloud amounts (CAH, CAM, CAL) by CA. The sum of the relative contributions, CAHR, CAMR and CALR is equal to 1 . Relative CA values give an indication of how the detected clouds are vertically distributed in the atmosphere, when observed from above. Global averages of AIRS-CIRS and IASICIRS are compared with those from selected cloud climatologies of the GEWEX Cloud Assessment database: the International Satellite Cloud Climatology Project (ISCCP; Rossow and Schiffer, 1999), two cloud climatologies derived from observations of the Moderate Resolution Imaging Spectroradiometer (MODIS) aboard the Aqua satellite, by the MODIS Science Team (MODIS-ST; Frey et al., 2008) and by the MODIS CERES Science Team (MODISCE; Minnis et al., 2011), and two cloud climatologies derived from CALIPSO observations, by the CALIPSO Science Team (CALIPSO-ST; Winker et al., 2009) and by the GCM-Oriented CALIPSO Cloud Products (CALIPSOGOCCP; Chepfer et al., 2010). The latter two use vertical averaging (CALIPSO-GOCCP) and horizontal averaging (CALIPSO-ST) to reduce the noise of the relatively small samples. The latter is more sensitive to thin layers of subvisible cirrus. ISCCP is essentially using two atmospheric window channels (IR and VIS, the latter only during daytime). Considering passive remote sensing, total CA from the GEWEX Cloud Assessment database is about $0.68 \pm 0.03$ (Stubenrauch et al., 2013), while CALIPSO-ST provides a CA of 0.73 because it includes subvisible cirrus.

We separately examine daytime and nighttime observations. While all data sets agree quite well on CA, with ISCCP and MODIS-CE providing smaller CA during night (both including VIS information for cloud detection during daytime), CAHR exhibits a large spread due to different sensitivity to thin cirrus: active lidar is the most sensitive, followed by IR sounders. The CIRS results are very similar to the results from the AIRS-LMD cloud climatology (Stubenrauch et al., 2010). The choice of ancillary data only slightly affects CA at night. IASI-CIRS and AIRS-CIRS results are also very similar, day and night. They present global averages of CA around $0.67-0.70$, formed by $40 \%$ high-level, $20 \%$ mid-level and $40 \%$ low-level uppermost clouds. This is in excellent agreement with the results from CALIPSO. The slightly smaller value in CALIPSO CAMR (14\% instead of $20 \%$ ) is due to the different distinction between high-level and mid-level clouds: CALIPSO uses cloud top 


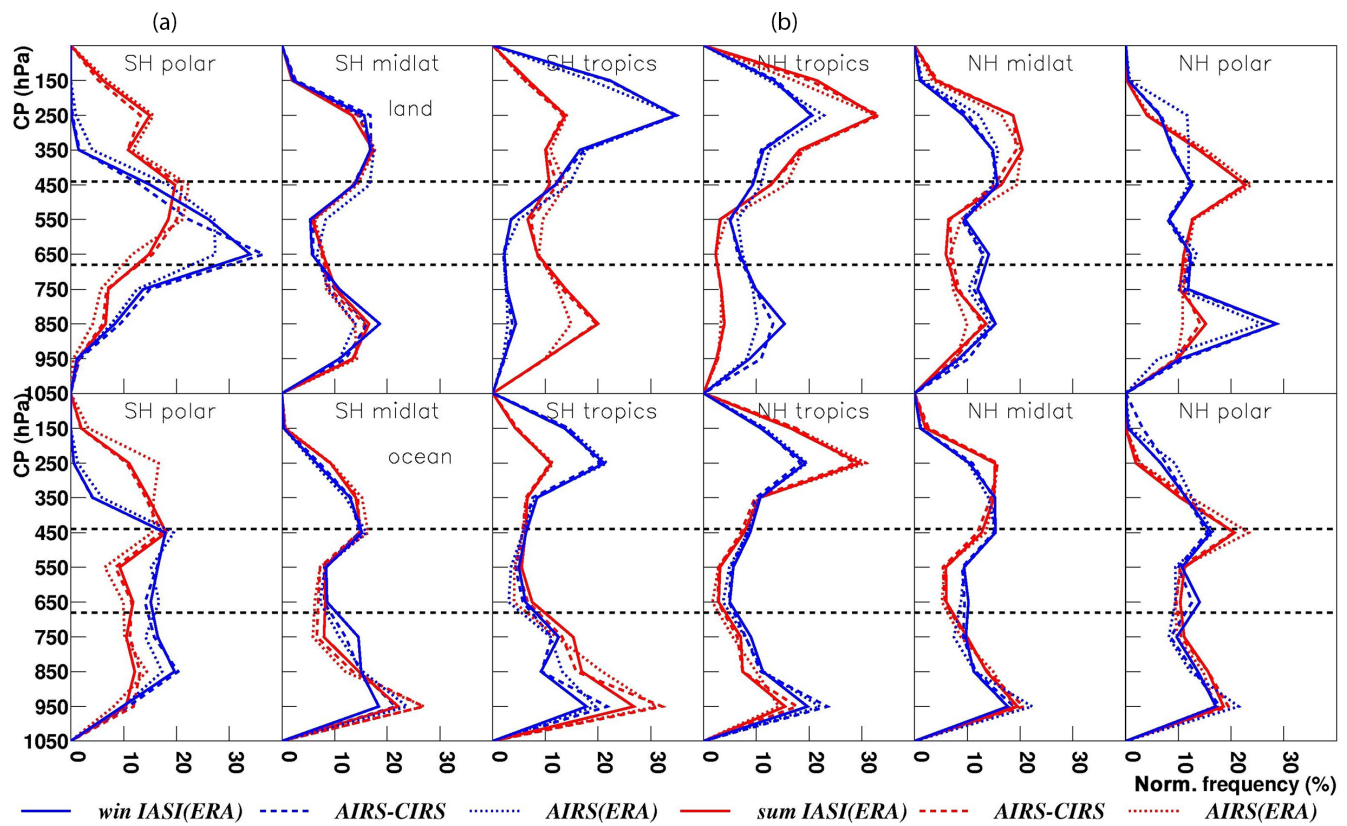

Figure 6. Normalized frequency distributions of $p_{\text {cld }}$, separately over land and over ocean in six latitude bands of $30^{\circ}$ from $\mathrm{SH}$ polar (a) to NH polar latitudes (b), in boreal winter (December, January, February; blue) and in boreal summer (June, July, August; red). Compared are results from AIRS-CIRS using two sets of ancillary data (AIRS-NASA, dashed line) and (ERA-Interim, dotted line), as well as from IASI-CIRS (full line) (statistics from 2008).

Table 2. Averages of CA, CAHR, CAMR and CALR (in \%) from AIRS-LMD (2003-2009); AIRS-CIRS (2003-2015), using AIRS-NASA and ERA-Interim ancillary data; and IASI-CIRS (2008-2015), using ERA-Interim ancillary data.

\begin{tabular}{lrrrr}
\hline Latitude band & CA $(\%)$ & CAHR $(\%)$ & CAMR $(\%)$ & CALR $(\%)$ \\
\hline Globe & $67 ; 67 ; 70 ; 67$ & $41 ; 41 ; 40 ; 40$ & $18 ; 19 ; 19 ; 20$ & $41 ; 40 ; 41 ; 40$ \\
Ocean & $72 ; 71 ; 74 ; 72$ & $38 ; 38 ; 37 ; 37$ & $16 ; 16 ; 17 ; 18$ & $47 ; 45 ; 46 ; 44$ \\
Land & $56 ; 57 ; 59 ; 56$ & $48 ; 49 ; 47 ; 47$ & $23 ; 25 ; 23 ; 23$ & $29 ; 27 ; 30 ; 30$ \\
$60-30^{\circ} \mathrm{N}$ & $69 ; 69 ; 72 ; 69$ & $40 ; 40 ; 40 ; 40$ & $22 ; 23 ; 22 ; 22$ & $38 ; 37 ; 38 ; 38$ \\
$15^{\circ} \mathrm{N}-15^{\circ} \mathrm{S}$ & $67 ; 63 ; 66 ; 62$ & $59 ; 58 ; 57 ; 58$ & $11 ; 10 ; 10 ; 11$ & $30 ; 32 ; 33 ; 31$ \\
$30-60^{\circ} \mathrm{S}$ & $80 ; 84 ; 85 ; 85$ & $28 ; 30 ; 30 ; 29$ & $21 ; 23 ; 22 ; 23$ & $51 ; 47 ; 48 ; 48$ \\
\hline
\end{tabular}

height, whereas AIRS and IASI use a cloud height about $1 \mathrm{~km}$ lower than the top (Sect. 3.2). When combining VIS and IR information in the retrieval, thin cirrus above low-level clouds tend to be misidentified as mid-level clouds (ISCCP) or as low-level clouds (MODIS), leading to a not-negligible underestimation of CAHR (30\% instead of $40 \%$ ). At night, when only the IR channel is available, ISCCP underestimates the height of all semi-transparent high-level clouds, so that CAHR drops to $15 \%$. When IR spectral information is available, as for IR sounders and MODIS, results are similar to those during daytime.

Differences between ocean and land, also presented in Fig. 7, correspond to about 0.15 in CA, with about $20 \%$ more low-level clouds over ocean and about $10 \%$ more highlevel and mid-level clouds over land. The CIRS retrievals provide similar values during day and night. It is interesting to note that during daytime the difference in CA shows a larger spread between the data sets, while at night the spread is larger for CALR. At night, low-level clouds are more difficult to detect, especially over land.

Table 2 summarizes averages of these cloud amounts over the whole globe, over ocean and over land, also contrasting $\mathrm{NH}$ and Southern Hemisphere (SH) midlatitudes $\left(30-60^{\circ}\right)$ and tropics $\left(15^{\circ} \mathrm{N}-15^{\circ} \mathrm{S}\right)$. The largest fraction of high-level clouds is situated in the tropics, while the largest fraction of single-layer low-level clouds in the SH midlatitudes. Only about $10 \%$ of all clouds in the tropics are single-layer midlevel clouds, compared to about $22 \%$ in the midlatitudes. As already discussed in Sects. 2.5 and 3.1, the uncertainty due to ancillary data in CA, as well as in CALR, is largest over land (about 5 and $10 \%$, respectively) because low-level clouds are underestimated with AIRS-NASA ancillary data during night and with ERA-Interim ancillary data in the afternoon. Uncertainties are much smaller for high-level clouds. Considering 

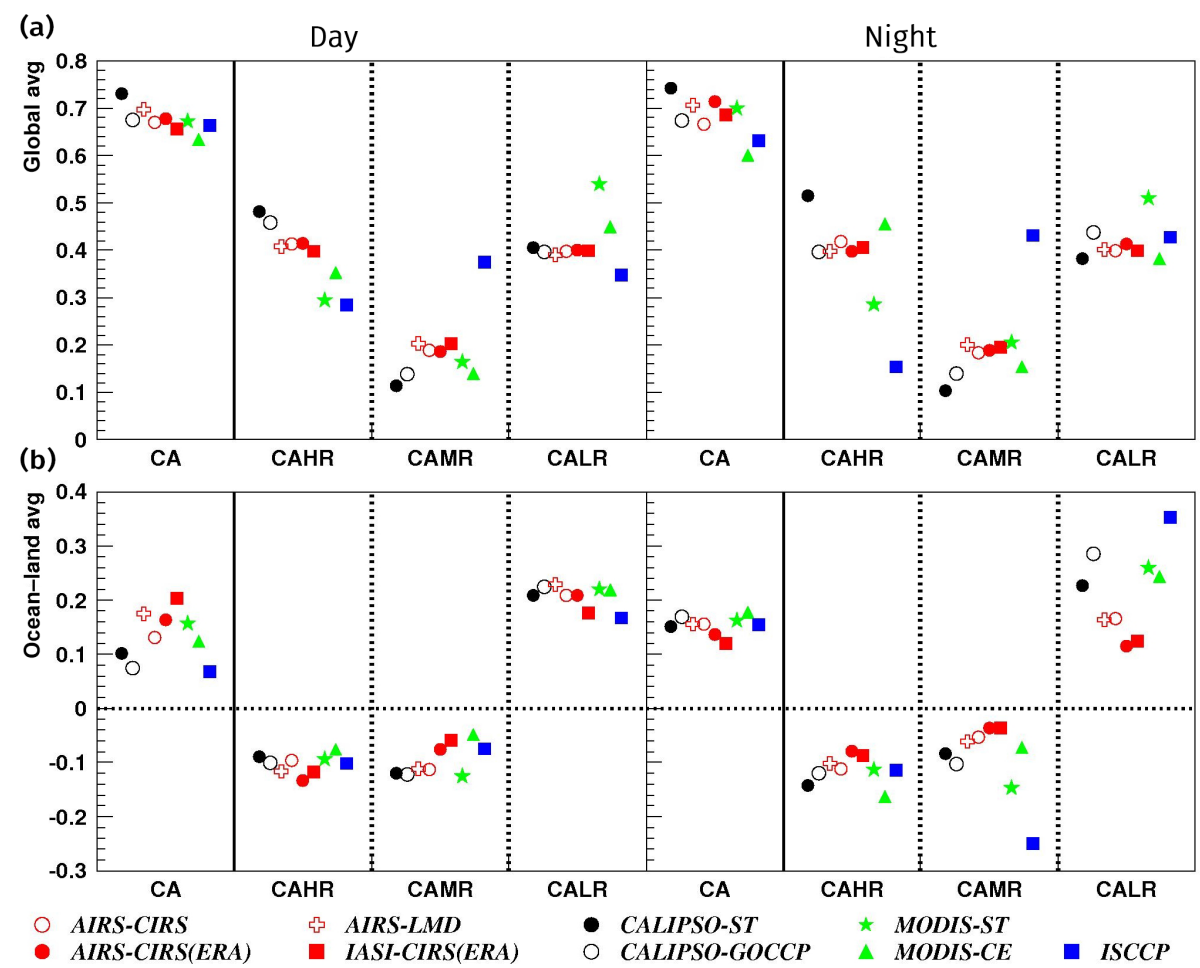

Figure 7. (a) Global averages of total cloud amount (CA) and fraction of high-level, mid-level and low-level cloud amount, relative to total cloud amount $(\mathrm{CAHR}+\mathrm{CAMR}+\mathrm{CALR}=1)$. Comparisons of IR sounder cloud data (AIRS, IASI) with L3 data from the GEWEX Cloud Assessment database, separately for observations mostly during day (13:30 LT; 15:00 LT for ISCCP and 09:30 LT for IASI, left) and mostly during night (01:30 LT; 03:00 LT for ISCCP and 21:30 LT for IASI). Compared to the original ISCCP data, the day-night adjustment on CA has not been included to better illustrate the differences between VIS-IR and IR-only results. (b) Averages of ocean-land differences for the same parameters and data sets.

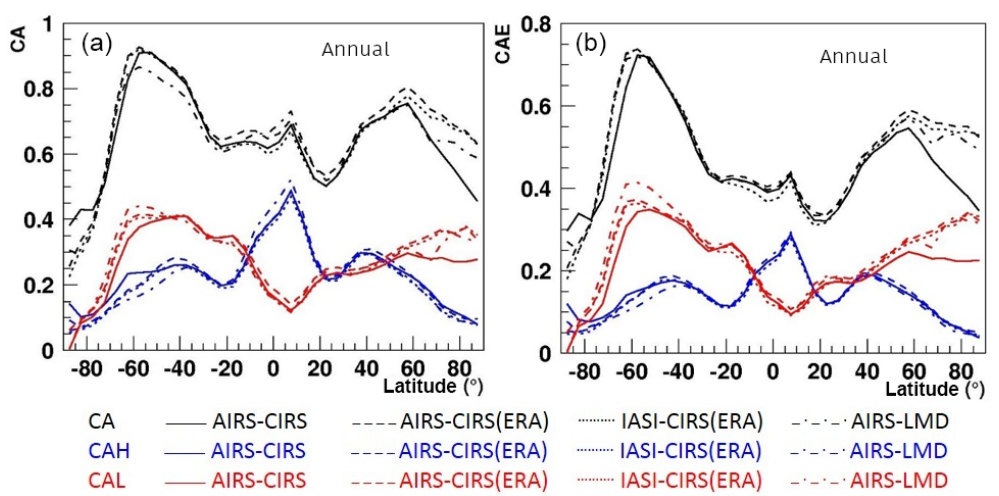

Figure 8. Annual mean zonal distributions of CA, CAH and CAL (a) and CAE, CAEH and CAEL (b). Results are compared between AIRS-CIRS, using ancillary data from AIRS-NASA and from ERA-Interim, IASI-CIRS and AIRS-LMD.

further three distinct high-level cloud classes, opaque, thick cirrus and thin cirrus (Sect. 2.5), high-level opaque clouds only represent about $5.2 \%$ of all clouds, while relative cloud amounts of thick cirrus and thin cirrus are about 21.5 and $13 \%$. Maximum values are observed in the tropics: 7.5, 27.5 and $21.5 \%$, respectively (Table 3). The independent use of $p_{\text {cld }}$ and $\varepsilon_{\text {cld }}$ enabled us to build a climatology of UT cloud systems, using $\varepsilon_{\text {cld }}$ to distinguish convective core, cirrus anvil and thin cirrus of these systems. These data have revealed for the first time that the $\varepsilon_{\text {cld }}$ structure of tropical anvils is related to the convective depth (Protopapadaki et al., 2017).

Figure 8 presents zonal averages of $\mathrm{CA}, \mathrm{CAH}$ and $\mathrm{CAL}$ as well as effective CA for total (CAE) high-level (CAEH) and low-level (CAEL) clouds for the three CIRS climatolo- 

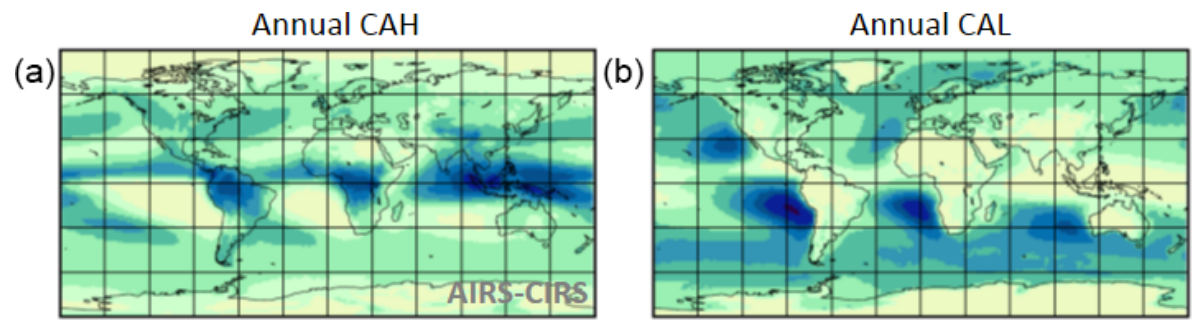

(c)

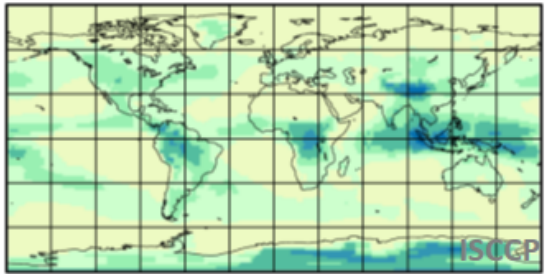

(e)

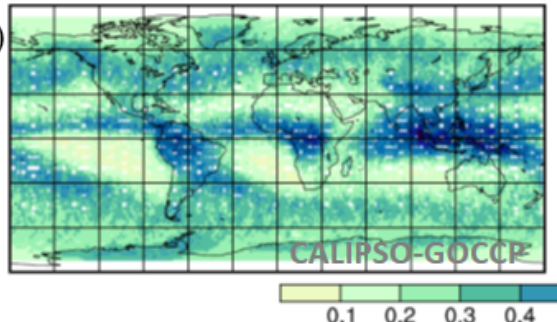

(d)

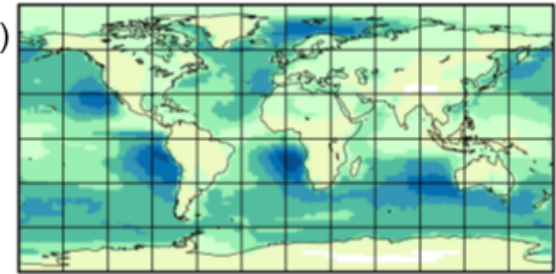

(f)

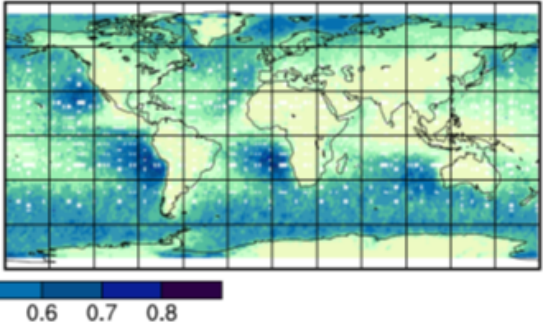

Figure 9. (a, b): Geographical maps of annual CAH (a, c, e) and CAL (b, d, f), from AIRS-CIRS (2003-2015, top), ISCCP (2003-2007, c, d) and CALIPSO-GOCCP (2007-2008, e, f), the latter two from the GEWEX Cloud Assessment database. White areas correspond to no data.

Table 3. Averages of relative amount (in $\%)$ of opaque $\left(\varepsilon_{\text {cld }}>0.95\right)$, cirrus $\left(0.95>\varepsilon_{\text {cld }}>0.5\right)$ and thin cirrus $\left(0.5>\varepsilon_{\text {cld }}>0.1\right)$ from AIRSCIRS (2003-2015), using AIRS-NASA and ERA-Interim ancillary data; and IASI-CIRS (2008-2015), using ERA-Interim ancillary data.

\begin{tabular}{lrrr}
\hline Latitude band & Opaque/total CA & Cirrus/total CA & Thin cirrus/total CA \\
\hline Globe & $5.3 ; 5.0 ; 5.4$ & $21.7 ; 21.5 ; 20.9$ & $13.4 ; 13.0 ; 12.9$ \\
Ocean & $5.0 ; 4.5 ; 4.9$ & $20.0 ; 19.9 ; 19.2$ & $12.5 ; 12.0 ; 12.1$ \\
Land & $6.1 ; 5.9 ; 6.6$ & $25.8 ; 25.3 ; 24.9$ & $15.6 ; 15.2 ; 14.7$ \\
$60-30^{\circ} \mathrm{N}$ & $5.4 ; 4.8 ; 5.4$ & $22.9 ; 23.5 ; 22.8$ & $11.1 ; 11.0 ; 10.9$ \\
$15^{\circ} \mathrm{N}-15^{\circ} \mathrm{S}$ & $7.3 ; 7.0 ; 7.7$ & $28.2 ; 27.5 ; 26.8$ & $21.6 ; 21.3 ; 22.1$ \\
$30-60^{\circ} \mathrm{S}$ & $4.8 ; 4.2 ; 4.4$ & $17.5 ; 18.9 ; 18.1$ & $6.9 ; 6.6 ; 5.9$ \\
\hline
\end{tabular}

gies (AIRS, using two sets of ancillary data, and IASI) and the prior AIRS-LMD cloud climatology. Effective CA corresponds to the CA weighted by cloud emissivity. It therefore includes the IR radiative effect of the detected clouds. In general, CAE is about 0.2 smaller than CA. Maximum CAH and CAEH appear in the ITCZ, while maximum CAL and CAEL is found in the SH midlatitudes. The results of all CIRS climatologies are very similar, with AIRS-CIRS using AIRS-NASA ancillary data presenting slightly more highlevel clouds and fewer low-level clouds around $60^{\circ} \mathrm{S}$ and slightly fewer CA and CAL in the NH polar region.

Figure 9 presents geographical maps of annual $\mathrm{CAH}$ and CAL. We compare AIRS-CIRS, ISCCP and CALIPSOGOCCP, the latter two from the GEWEX Cloud Assessment database. In all data sets the most prominent feature in CAH is the ITCZ. However, due to the better sensitivity to cirrus, the absolute values are more pronounced for AIRSCIRS (IASI-CIRS, not shown) and CALIPSO-GOCCP than for ISCCP. Due to the narrow nadir track of CALIPSO and the reduced statistics of CALIPSO-GOCCP in the present GEWEX Cloud Assessment database, these data look noisier than AIRS-CIRS and ISCCP. Considering CAL, AIRS-CIRS captures well the stratocumulus regions off the west coasts of the continents and stratus decks in the subtropical subsidence regions in winter, even if this type of cloud is easier to detect by using instruments including VIS channels (during daytime, ISCCP) or active instruments (CALIPSO-GOCCP).

Time series of deseasonalized anomalies in global monthly mean CA, CAEH and CAEL of the three CIRS data sets are shown in Fig. 10 over the time period of 2004-2016 for 
AIRS and 2008-2016 for IASI. To illustrate the effect of the calibration accounting for changes in atmospheric $\mathrm{CO}_{2}$ concentration (Sect. 2.5.2), the time series of the AIRS-CIRS $\mathrm{CA}$ anomalies, without this correction, is added. Whereas the uncorrected CA anomalies increase by about 0.040 within a decade, the magnitude of the calibrated CA and CAEL variations lie within 0.010 and of CAEH within 0.005 , being mostly stable within the uncertainty range.

Latitudinal seasonal cycles of CA, CAH, CAL and $T_{\text {cld }}$ (CT) from the different data sets agree in general quite well (Fig. S4 of the Supplement). The most prominent features of the latitudinal seasonal cycles are (i) the shift of the ITCZ towards the summer hemisphere, seen as an amplitude of 0.1 in $\mathrm{CA}, 0.3$ in $\mathrm{CAH}$ and $16 \mathrm{~K}$ in $\mathrm{CT}$ in the $\mathrm{SH}$ and $\mathrm{NH}$ tropical bands (mostly over land, not shown) and (ii) fewer clouds in late summer in the midlatitudes (mostly over ocean and stronger in $\mathrm{NH}$, not shown). The seasonal cycle of $\mathrm{CT}$ is largest in the polar regions (coherent for all data sets) and smallest in SH midlatitudes, with amplitudes ranging from 20 to $10 \mathrm{~K}$. However, while the CT amplitude is linked to change in cloud height at low latitudes, it is more related to change in atmospheric temperature (and corresponding CT) at higher latitudes.

\section{Applications}

After having demonstrated the reliability of the CIRS cloud climatologies in Sects. 3 and 4, we present analyses on UT cloud variability with respect to changes in atmospheric conditions. These illustrate the added value of the CIRS cloud data for climate studies.

\subsection{Hemispheric differences in UT clouds}

While the $\mathrm{NH}$ and the $\mathrm{SH}$ reflect the same amount of sunlight within $0.2 \mathrm{Wm}^{-2}$ (Stephens et al., 2015), there is a small energy imbalance between both hemispheres of our planet, with slightly more energy absorbed by the $\mathrm{SH}\left(0.9 \mathrm{Wm}^{-2}\right)$. This yields more frequent precipitation in the $\mathrm{SH}$ and more intense precipitation in the NH (Stephens et al., 2016). The latter might be linked to the characteristics of the ITCZ, a zone of strong convection, which itself produces large cirrus anvils. As the size of these anvils is on average positively related to convective strength (e. g. Protopapadaki et al., 2017), we explore the annual mean and seasonal hemispheric difference of high CA and try to relate it to the characteristics of the ITCZ, such as its peak strength, the latitudinal position of the peak and its width.

The ITCZ characteristics have been determined by fitting a Gaussian around the tropical peak of the latitudinal CAH distributions (Fig. 8), per month and year. This yields the latitude of the peak position, the value of the peak itself and the width of the tropical CAH distribution. From Fig. 11 we deduce that the annual $\mathrm{NH}-\mathrm{SH}$ difference in $\mathrm{CAH}$ is 0.05 , with a pronounced seasonal cycle of about 0.3 in amplitude. Results from the three CIRS cloud climatologies (AIRS with two ancillary data sets and IASI), AIRS-LMD, CALIPSOGOCCP, ISCCP and MODIS-CE are similar. This seasonal cycle is well related to the one of the ITCZ peak latitude, which moves up to $12^{\circ} \mathrm{N}$ in July. It is interesting to note that the width of the ITCZ is smaller in July and August (10.5$\left.12.5^{\circ}\right)$ than in January $\left(17^{\circ}\right)$ and the CAH peak is about $10 \%$ larger in August than in January. This might suggest a more intense ITCZ (and hence more intense precipitation) when it is located in the $\mathrm{NH}$ than when it is located in the $\mathrm{SH}$.

All data sets agree well on the ITCZ peak latitude. The smaller maximum CAH values of MODIS-CE and ISCCP are due to smaller sensitivity to thin cirrus, and the reduced seasonal cycle of maximum CAH and of ITCZ width for CALIPSO-GOCCP is due to the inclusion of ubiquitous thinner cirrus, leading to less-well-pronounced $\mathrm{CAH}$ minima in the subtropics. The CIRS climatologies reveal the seasonal behaviour of the ITCZ characteristics clearly. Figure 11 confirms and extends the interpretation of the results of Stephens et al. (2016) by displaying a relation between the hemispheric difference of CAH and characteristics of the ITCZ, which seems to be more intense when its peak is situated in the $\mathrm{NH}$ (smaller width and larger maximum).

\subsection{Relating surface temperature anomalies to changes in UT clouds}

Since the observational period of AIRS and IASI is too short to directly study long-term cloud variability related to climate warming, an alternative approach is to analyse cloud variability in response to interannual climate variability. Though interannual global mean surface temperature anomalies might not directly relate to patterns of anthropogenic climate warming, Zhou et al. (2015) have shown that interannual cloud feedback may be used to directly constrain the long-term cloud feedback. Changes in tropical UT clouds lead to variations in atmospheric heating and cooling, which then may influence the large-scale circulation, as has already been shown by Slingo and Slingo (1991).

Since the radiative effects of high opaque clouds and thin cirrus are quite different, we investigate the geographical patterns of UT cloud amount anomalies with respect to tropical and global mean surface temperature anomalies, by separating them into opaque, cirrus and thin cirrus $\left(\varepsilon_{\text {cld }}>0.95,0.4\right.$ 0.95 and $<0.4$, corresponding to visible COD $>6,1-6$ and $<1$, respectively). By making use of the whole period between 2003 and 2015 (covering 156 months), we estimate a change in UT cloud amount as a function of change in mean surface temperature by a linear regression of their deseasonalized monthly anomalies, at a spatial resolution of $1^{\circ}$ latitude $\times 1^{\circ}$ longitude. Similar techniques were already utilized in other studies related to El Niño-Southern Oscillation (ENSO) and cloud feedback (e.g. Lloyd et al., 2012; Zhou et al., 2013; Liu et al., 2017). Figure 12 presents the 

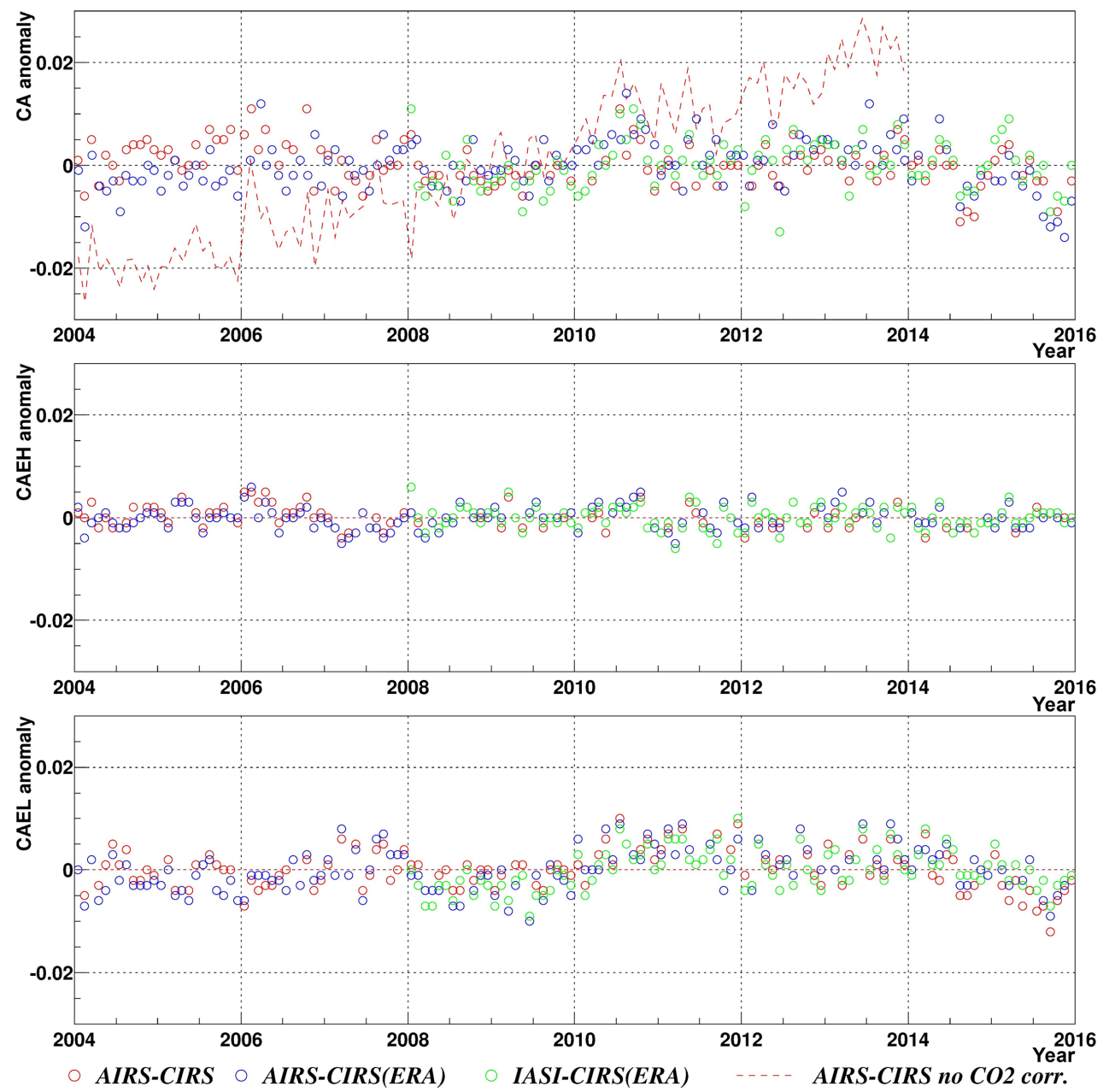

Figure 10. Time anomalies of deseasonalized CA, CAEH and CAEL over the globe. In the case of CA, additional values are shown without calibration of spectral atmospheric transmissivities for changes in atmospheric $\mathrm{CO}_{2}$ concentration.

change in amount of high opaque cloud (mostly of convective origin), in thick cirrus (often formed from convective outflow as anvils) and in thin cirrus (which might be formed as anvil or via in situ freezing) per kelvin of global surface warming, obtained as the linear slopes of these deseasonalized monthly anomaly relationships. The cloud amounts are from AIRS-CIRS, while the surface temperatures are from the ERA-Interim ancillary data. Results are very similar when using $T_{\text {surf }}$ anomalies from AIRS-NASA (not shown). Zhou et al. (2013) have shown that ERA-Interim $T_{\text {surf }}$ anomalies give similar results in their short-term cloud feedback analysis compared to other $T_{\text {surf }}$ data sets. In our study, we concentrate on the change of UT clouds of different height ( $p_{\text {cld }}<440 \mathrm{hPa}$ and $p_{\text {cld }}<330 \mathrm{hPa}$ ), and we compare changes in absolute UT cloud amounts and in UT cloud amounts relative to total cloud amount. The geographical patterns of the relative slope uncertainty are shown in Fig. S5 in the Supplement. In general, large changes in cloud amount per $\mathrm{K}$ of warming have smaller uncertainty than small ones, indicating robust patterns.

During this period, global mean $T_{\text {surf }}$ anomalies and tropical mean $T_{\text {surf }}$ anomalies are strongly correlated (not shown), and the spatial patterns in Fig. 12 are compatible with ENSOlike patterns. The left panels of Fig. 12 agree quite well with Fig. 8 of Liu et al. (2017), based on MODIS cloud amount and HadCRUT4 $T_{\text {surf }}$ anomalies, even though our cloud types categories differ slightly. In particular, we have separated thin cirrus. Therefore the analyses suggest that the change patterns address ENSO variability rather than long-term trends. When considering relative cloud type changes (middle panels in Fig. 12), the signals are stronger. An interesting feature appears when considering changes in the relative amounts of higher clouds ( $p_{\text {cld }}<330 \mathrm{hPa}$, left panels of Fig. 12): while the high opaque clouds, linked to strong precipitation (Protopapadaki et al., 2017), relative to all clouds, increase in a narrow band in the tropics, there is a large increase in relative thin cirrus amount around these regions; the latter might 


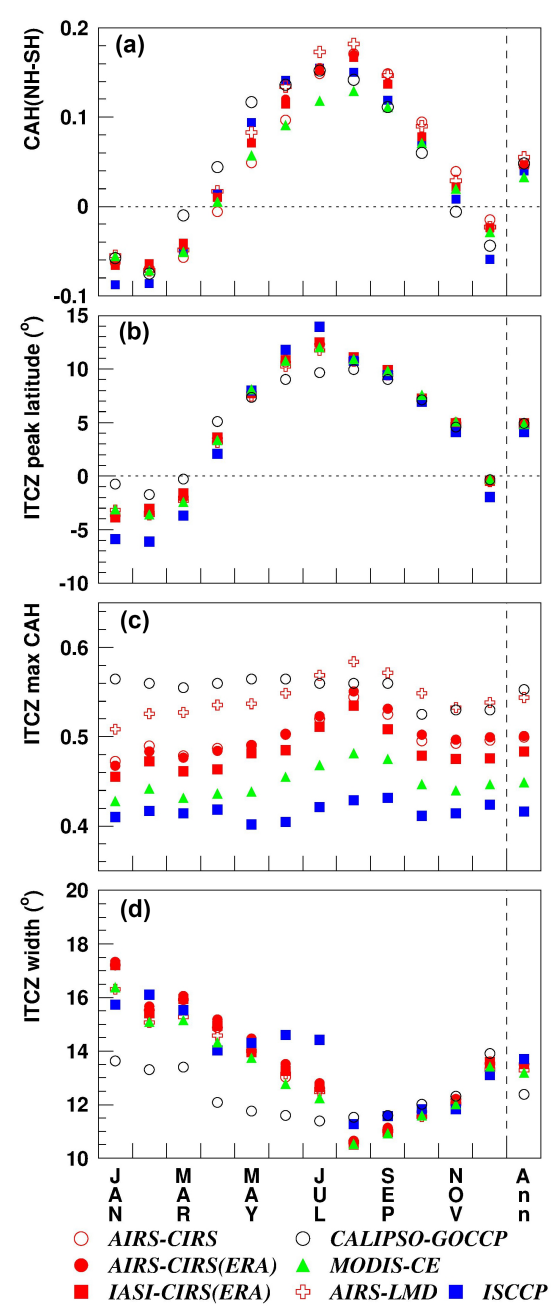

Figure 11. Seasonal cycle/annual average of (a) $\mathrm{CAH}$ differences between $\mathrm{NH}\left(0-60^{\circ} \mathrm{N}\right)$ and $\mathrm{SH}\left(0-60^{\circ} \mathrm{S}\right)$, (b) ITCZ peak latitude, (c) maximum CAH within ITCZ and (d) width of ITCZ.

directly affect the atmospheric circulation through their radiative heating (e.g. Sohn, 1999; Lebsock et al., 2010).

As in Liu et al. (2017), we have also examined linear regression slopes from anomaly averages over the tropics and other latitudinal bands. Although in general the relationships are very noisy, on the interannual scale tropical cirrus amount slightly decreases with warming $\left(-0.76 \pm 0.21 \% \mathrm{~K}^{-1}\right)$, while thin cirrus amount seems not affected $\left(-0.09 \pm 0.20 \% \mathrm{~K}^{-1}\right)$, in agreement with Liu et al. (2017). However, when considering changes in tropical cirrus and thin cirrus amount relative to total cloud amount, at higher altitude ( $p_{\text {cld }}<330 \mathrm{hPa}$ ), both increase with warming $\left(1.87 \pm 0.52\right.$ and $\left.1.70 \pm 0.54 \% \mathrm{~K}^{-1}\right)$, which means that these clouds are more frequent among all clouds when $T_{\text {surf }}$ gets warmer.

Even though the changes in mean $T_{\text {surf }}$ are mostly linked to interannual variability over the studied period and it is still uncertain how to relate these to long-term patterns due to anthropogenic climate warming, it is very interesting to note that changes in amounts of high opaque clouds and thin cirrus, relative to all clouds, show very different geographical patterns. To get a better understanding on the underlying feedback processes one has to consider the heating rates of these UT cloud systems and link them to the dynamics, which is foreseen in future work.

\section{Conclusions}

We have presented two global climatologies of cloud properties, built from AIRS and IASI observations by the CIRS cloud retrieval. This retrieval software package, developed at LMD, can be easily adapted to any IR sounder. The retrieval method itself, based on a weighted $\chi^{2}$ method on radiances along the wing of the $15 \mu \mathrm{m} \mathrm{CO}_{2}$ absorption band, and a multi-spectral "a posteriori" cloud detection, based on the spectral coherence of retrieved cloud emissivities, have been evaluated in previous publications. In this study, we have further demonstrated the reliability of these updated cloud climatologies. IR sounders are especially advantageous to retrieve UT cloud properties, as they reliably determine cirrus properties down to an IR optical depth of 0.1 , day and night. The CIRS retrieval uses improved radiative transfer modelling, employs the latest ancillary data (surface temperature, atmospheric profiles) and accounts for atmospheric spectral transmissivity changes associated with latitudinal, seasonal and interannual atmospheric $\mathrm{CO}_{2}$ concentration variations. The latter eliminates an artificial CA trend of about $4 \%$ over the observation period of 2004 to 2016: The magnitude of cloud amount and effective low-level cloud amount deseasonalized variations lies within $1 \%$ and that of effective highlevel cloud amount lies within $0.5 \%$ over this period.

Ancillary data from the meteorological reanalyses ERAInterim have been interpolated to the observation times of AIRS and IASI. Additional ancillary data, established from NASA AIRS retrievals, permitted us to iteratively make adjustments to both sets of ancillary data for optimal results in cloud properties and to estimate uncertainties in cloud amounts. Since the cloud detection depends on the coherence of spectral cloud emissivity, the surface temperature influences only slightly the cloud amount (in particular the one of low-level clouds). AIRS total cloud amount is $70 \%(67 \%)$, high-level cloud amount is $27 \%(27 \%)$ and low-level cloud amount is $29 \%(27 \%)$, using ERA-Interim (AIRS-NASA) ancillary data. This corresponds to uncertainty estimates of $5 \%$ and $10 \%$ on global averages of CA and CAL, respectively. Uncertainties are larger over land and ice or snow than over ocean, in particular because $T_{\text {surf }}$ of ERA-Interim is underestimated in the afternoon and $T_{\text {surf }}$ of AIRS-NASA is underestimated during night due to cloud contamination. In the future, the CIRS cloud retrieval might use ancillary data from the new ECMWF meteorological reanalysis ERA5, with a better temporal and spatial resolution. 

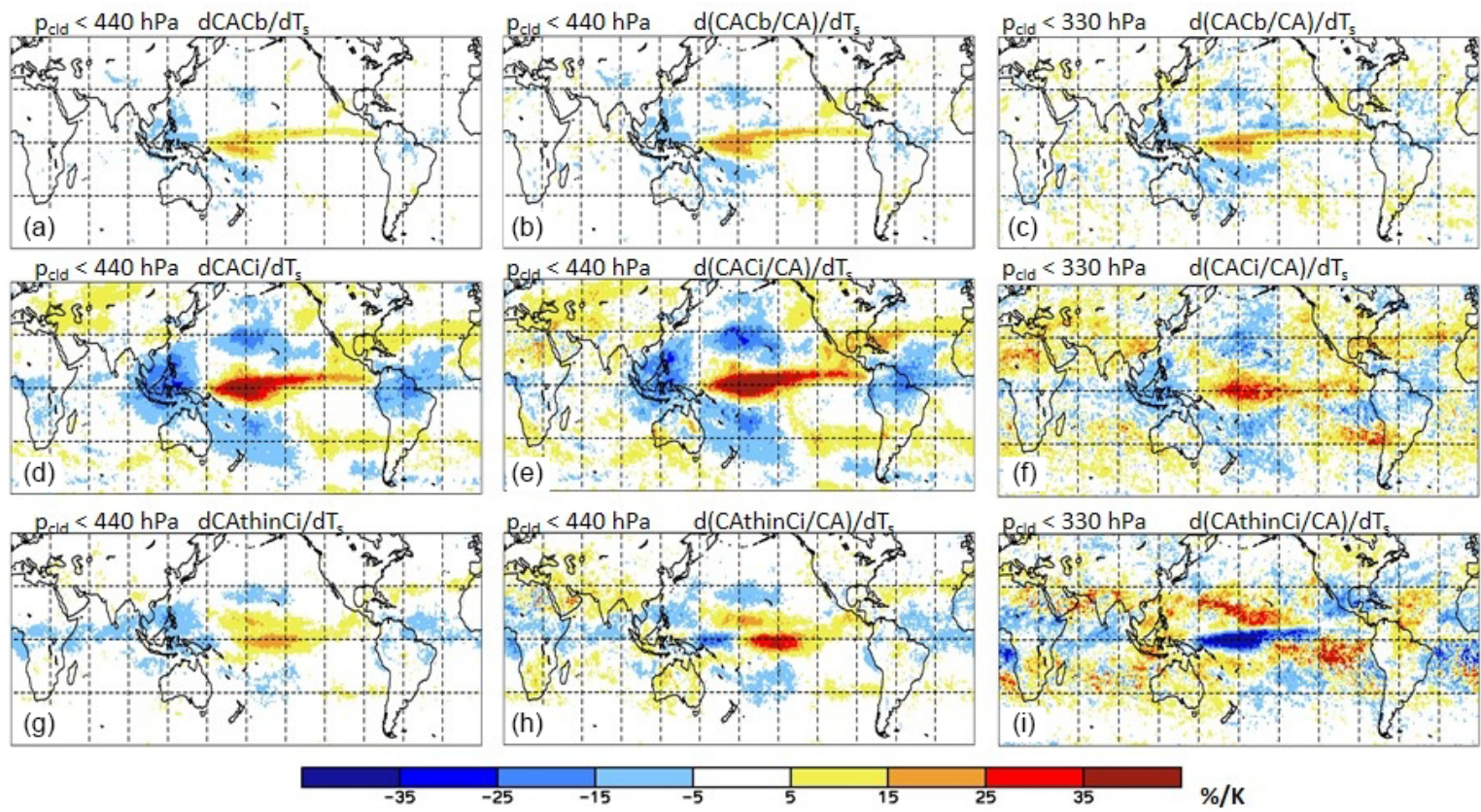

Figure 12. Geographical maps of linear regression slopes between monthly mean anomalies in amount of $\mathrm{Cb}\left(\varepsilon_{\mathrm{cld}}>0.95 ; \mathbf{a}-\mathbf{c}\right)$, $\mathrm{Ci}$ $\left(0.95>\varepsilon_{\text {cld }}>0.4 ; \mathbf{b}, \mathbf{d}, \mathbf{h}\right)$ and thin $\mathrm{Ci}\left(0.4>\varepsilon_{\text {cld }}>0.1 ; \mathbf{g}-\mathbf{i}\right)$ from AIRS-CIRS and global mean surface temperature anomalies from ERAInterim. (a, d, g) $p_{\text {cld }}<440 \mathrm{hPa}$; (d-f) relative cloud amount; (c, f, i) $p_{\text {cld }}<330 \mathrm{hPa}$ and relative cloud amount. Results using $156 \mathrm{months}$ during the period 2003-2015.

Cloud detection hit rates between AIRS-CIRS and CALIPSO-CloudSat are $84 \%(85 \%)$ over ocean, $82 \%$ $(79 \%)$ over land and $70 \%(73 \%)$ over ice and snow for ERA-Interim (AIRS-NASA) ancillary data. Typical $p_{\text {cld }}$ uncertainties range from $30 \mathrm{hPa}$ for high-level clouds to $120 \mathrm{hPa}$ for low-level clouds, which corresponds to about $1.2 \mathrm{~km}$. A comparison with CALIPSO-CloudSat shows that on average the CIRS retrieved cloud height is close to cloud top in the case of low-level clouds and lies about $1 \mathrm{~km}$ below cloud top in the case of high-level clouds. The latter leads to retrieved cloud temperatures which are about $10 \mathrm{~K}$ warmer than the cloud top. This has to be considered when determining radiative effects or when evaluating climate models. The CIRS retrieved cloud height can be approximated by the mean layer height (for optically thin clouds) or the mean between cloud top and the height at which the cloud reaches opacity, for both high-level and low-level clouds. While for low-level clouds this vertical distance is about $0.5 \mathrm{~km}$, for high-level clouds it slightly increases with $\varepsilon_{\text {cld }}$ from 0.7 to $1.5 \mathrm{~km}$, with slightly larger values in the tropics than in the midlatitudes, linked to diffusive cloud tops.

Total cloud amount is partitioned into about $40 \%$ highlevel clouds, $40 \%$ low-level clouds and $20 \%$ mid-level clouds. The latter two categories are only detected in the absence of upper clouds. UT clouds are most abundant in the tropics, where high opaque clouds make up $7.5 \%$, thick cirrus $27.5 \%$ and thin cirrus $21.5 \%$ of all clouds. IASI values are very similar. The most prominent feature of latitudinal seasonal cycles is the shift of the ITCZ towards the summer hemisphere, seen as an amplitude signal of 0.1 in CA, 0.3 in $\mathrm{CAH}$ and $16 \mathrm{~K}$ in $\mathrm{CT}$ in the $\mathrm{SH}$ and $\mathrm{NH}$ tropical bands (and even stronger over land).

The $5 \%$ annual mean excess in UT cloud amount in the $\mathrm{NH}$ compared to the $\mathrm{SH}$ has a pronounced seasonal cycle with a maximum of $25 \%$ in boreal summer have been related to the characteristics of the ITCZ. The annual mean ITCZ peak latitude lies about $5^{\circ} \mathrm{N}$ with a maximum of $10^{\circ} \mathrm{N}$ in boreal summer. At that time the ITCZ width is also narrower and the peak slightly larger. This suggests that the $\mathrm{NH}-\mathrm{SH}$ excess in CAH is mostly determined by the position of the ITCZ.

To illustrate the added value of the CIRS cloud data for climate studies, we have finally presented geographical patterns in changes of amount of high opaque, cirrus and thin cirrus with respect to global mean $T_{\text {surf }}$ changes. These are in agreement with earlier studies, while an examination of changes in tropical high cirrus and thin cirrus amounts relative to total cloud amount revealed that these are more frequent among all clouds when $T_{\text {surf }}$ gets warmer. Even though the change in mean $T_{\text {surf }}$ is mostly linked to ENSO variability over the studied period and it is still uncertain how to relate these to long-term patterns due to anthropogenic climate warming, the large difference in geographical patterns in changes of amounts of high opaque clouds and thin cirrus, relative to total cloud amount, indicates that their response to climate change may be different. This might then have consequences 
on the atmospheric circulation. To get a better understanding on the underlying feedback processes, one has to consider the heating rates of these UT cloud systems and link them to the dynamics. Therefore the AIRS-CIRS and IASI-CIRS cloud data have been further used to build UT cloud systems (based on $p_{\text {cld }}$ ) and then to distinguish convective cores, cirrus anvil and thin cirrus according to $\varepsilon_{\text {cld }}$ (Protopapadaki et al., 2017). These data are being further exploited, together with other data and modelling on different scales, within the framework of the GEWEX Process Evaluation Study on Upper Tropospheric Clouds and Convection (UTCC PROES; Stubenrauch and Stephens, 2017) to advance our understanding on UT cloud feedbacks.

The AIRS-CIRS and IASI-CIRS cloud climatologies will be made available at the French data centre AERIS, which also will continue their production.

Data availability. AIRS L1 data are available at https://mirador. gsfc.nasa.gov/ (AIRS Science Team/Chahine, 2007). The NASA Science Team L2 standard products (version 6; AIRS Science Team/Texeira, 2013) are available at https://mirador.gsfc.nasa. gov/. IASI L1 data are available at the French Data Centre AERIS. The ARSA database can be obtained at http://ara.abct. lmd.polytechnique.fr/index.php?page=arsa. The operational version of the 4A radiative transfer model (Scott and Chédin, 1981) is available at http://4aop.noveltis.com/. The cloud climatologies of the GEWEX Cloud Assessment database are available at http://climserv.ipsl.polytechnique.fr/gewexca/. The AIRS-CIRS and IASI-CIRS cloud climatologies will be made available by the French Data Centre AERIS.

\section{The Supplement related to this article is available online at https://doi.org/10.5194/acp-17-13625-2017- supplement.}

Competing interests. The authors declare that they have no conflict of interest.

Acknowledgements. This work has been financially supported by CNRS, by the ESA Cloud_cci project (contract no. 4000109870/13/I-NB) and by CNES. The authors thank the members of the IASI, AIRS, CALIPSO and CloudSat science teams for their efforts and cooperation in providing the data as well as the engineers and space agencies who control the data quality. We thank the Aeris data infrastructure for providing access to the data used in this study and for continuing the data production. We also thank Filipe Aires for providing the surface emissivity climatology built from IASI. In addition, we thank two anonymous referees for their thoughtful comments, which improved the quality of the manuscript.

Edited by: Stefan Buehler

Reviewed by: two anonymous referees

\section{References}

Aires, F., Prigent, C., and Rossow, W. B.: Temporal interpolation of global surface skin temperature diurnal cycle over land under clear and cloudy conditions, J. Geophys. Res., 109, D04313, https://doi.org/10.1019/2003JD003527, 2004.

AIRS Science Team/Chahine, M.: AIRS/Aqua L1B Infrared (IR) geolocated and calibrated radiances V005, Greenbelt, MD, USA, Goddard Earth Sciences Data and Information Services Center (GES DISC), available at: https://disc.gsfc.nasa.gov/ datacollection/AIRIBRAD_005.html, 2007.

AIRS Science Team/Joao Texeira: AIRS/Aqua L2 Standard Physical Retrieval (AIRS + AMSU) V006, Greenbelt, MD, USA, Goddard Earth Sciences Data and Information Services Center (GES DISC), https://doi.org/10.5067/AQUA/AIRS/DATA201, 2013.

Blackwell, W. J., Milstein, A. B., Zavodsky, B., and Blankenship, C. B.: Neural Network Estimation of Atmospheric Thermodynamic State for Weather Forecasting Applications, Foundations of Augmented Cognition. Advancing Human Performance and Decision-Making through Adaptive Systems: 8th International Conference, AC 2014, Held as Part of HCI International 2014, Heraklion, Crete, Greece, 22-27 June, 93-103, Springer International Publishing, https://doi.org/10.1007/978-3-319-07527-3_9, 2014.

Chahine, M. T., Pagano, T. S., Aumann, H. H., Atlas, R., Barnet, C., Blaisdell, J., Chen, L., Divakarla, M., Fetzer, E. J., Goldberg, M., Gautier, C., Granger, S., Hannon, S., Irion, F. W., Kakar, R., Kalnay, E., Lambrigtsen, B. H., Lee, S., Le Marshall, J., McMillan, W. W., McMillin, L., Olsen, E. T., Revercomb, H., Rosenkranz, P., Smith, W. L., Staelin, D., Strow, L. L., Susskind, J., Tobin, D., Wolf, W., and Zhou, L.: AIRS: Improving weather forecasting and providing new data on greenhouse gases, B. Am. Meteorol. Soc., 87, 911-926, 2006.

Chédin, A., Scott, N. A., Wahiche, C., and Moulinier, P.: The improved initialization inversion method: A high resolution physical method for temperature retrievals from satellites of the TIROS-N series, J. Clim. Appl. Meteor., 24, 128-143, 1985.

Chédin, A., Serrar, S., Scott, N. A., Crevoisier, C., and Armante, R.: First global measurement of midtropospheric $\mathrm{CO}_{2}$ from NOAA polar satellites: Tropical zone, J. Geophys. Res., 108, 45814593, https://doi.org/10.1029/2003JD003439, 2003.

Chepfer, H., Bony, S., Winker, D., Cesana, G., Dufresne, J. L., Minnis, P., Stubenrauch, C. J., and Zeng, S.: The GCM Oriented Calipso Cloud Product (CALIPSO-GOCCP), J. Geophys. Res., 115, D00H16, https://doi.org/10.1029/2009JD012251, 2010.

Chevallier, F., Cheruy, F., Scott, N. A., and Chédin, A.: A neural network approach for a fast and accurate computation of longwave radiative budget, J. Appl. Meteorol., 37, 1385-1397, 1998.

Crevoisier, C., Clerbaux, C., Guidard, V., Phulpin, T., Armante, R., Barret, B., Camy-Peyret, C., Chaboureau, J.-P., Coheur, P.F., Crépeau, L., Dufour, G., Labonnote, L., Lavanant, L., HadjiLazaro, J., Herbin, H., Jacquinet-Husson, N., Payan, S., Péquignot, E., Pierangelo, C., Sellitto, P., and Stubenrauch, C.: Towards IASI-New Generation (IASI-NG): impact of improved spectral resolution and radiometric noise on the retrieval of thermodynamic, chemistry and climate variables, Atmos. Meas. Tech., 7, 4367-4385, https://doi.org/10.5194/amt-7-4367-2014, 2014.

Dee, D. P., Uppala, S. M., Simmons, A. J., Berrisford, P., Poli, P., Kobayashi, S., Andrae, U., Balmaseda, M. A., Balsamo, G., 
Bauer, P., Bechtold, P., Beljaars, A. C. M., van de Berg, L., Bidlot, J., Bormann, N., Delsol, C., Dragani, R., Fuentes, M., Geer, A. J., Haimberger, L., Healy, S. B., Hersbach, H., Holm, E. V., Isaksen, L., Kallberg, P., Kohler, M., Matricardi, M., McNally, A. P., Monge-Sanz, B. M., Morcrette, J.-J., Park, B.-K., Peubey, C., de Rosnay, P., Tavolato, C., Thepaut, J.-N., and Vitart, F.: The ERA-Interim reanalysis: configuration and performance of the data assimilation system, Q. J. Roy. Meteor. Soc., 137, 553-597, 2011.

Feofilov, A. and Stubenrauch, C.: LMD Cloud Retrieval using IR sounders. Algorithm Theoretical Basis, CIRS-LMD software package V2, $19 \mathrm{pp}$., https://doi.org/10.13140/RG.2.2.15812.63361, 2017.

Feofilov, A. G., Stubenrauch, C., and Armante, R.: Diurnal variation of cloud properties from the synergy of AIRS and IASI infrared sounders, EUMETSAT 2015 conference oral proceedings, session 5, $8 \mathrm{pp}$., available at: http://www.eumetsat.int/website/home/News/ ConferencesandEvents/DAT_2305526.html, session 5, oral proceedings, or at: https://goo.gl/UCitVZbyhttps://goo.gl/UCitVZ (last access: 10 November 2017) 2015a.

Feofilov, A. G., Stubenrauch, C. J., and Delanoë, J.: Ice water content vertical profiles of high-level clouds: classification and impact on radiative fluxes, Atmos. Chem. Phys., 15, 12327-12344, https://doi.org/10.5194/acp-15-12327-2015, 2015b.

Frey, R. A., Ackerman, S. A., Liu, Y., Strabala, K. I., Zhang, H., Key, J., and Wang, X.: Cloud Detection with MODIS, Part I: Recent Improvements in the MODIS Cloud Mask, J. Atmos. Ocean. Tech., 25, 1057-1072, 2008.

GLOBALVIEW-CO2: Cooperative Global Atmospheric Data Integration Project, 2013, updated annually, Multilaboratory compilation of synchronized and gap-filled atmospheric carbon dioxide records for the period 1979-2012 (obspack_co2_1_GLOBALVIEW-CO2_2013_v1.0.4_2013-1223). Compiled by NOAA Global Monitoring Division: Boulder, Colorado, USA, https://doi.org/10.3334/OBSPACK/1002, 2013.

Henderson, D. S., L'Ecuyer, T., Stephens, G. L., Partain, P., and Sekiguchi, M.: A Multisensor Perspective on the Radiative Impacts of Clouds and Aerosols, J. Appl. Meteorol. Climatol., 52, 853-871, https://doi.org/10.1175/JAMC-D-12-025.1, 2013.

Hilton, F., Armante, R., August, T., Barnet, C., Bouchard, A., Camy-Peyret, C., Capelle, V., Clarisse, L., Clerbaux, C., Coheur, P.-F., Collard, A., Crevoisier, C., Dufour, G., Edwards, D., Faijan, F., Fourrié, N., Gambacorta, A., Goldberg, M., Guidard, V., Hurtmans, D., Illingworth, S., Jacquinet-Husson, N., Kerzenmacher, T., Klaes, D., Lavanant, L., Masiello, G., Matricardi, M., McNally, A., Newman, S., Paveli, E., Payan, S., Péquignot, E., Peyridieu, S., Phulpin, T., Remedios, J., Schlüssel, P., Serio, C., Strow, L., Stubenrauch, C. J., Taylor, J., Tobin, D., Wolf, W., and Zhou, D.: Hyperspectral Earth Observation from IASI, B. Am. Meteorol. Soc., 93, 347-370, https://doi.org/10.1175/BAMS-D11-00027.1, 2012.

Hori, M., Aoki, T., Tanikawa, T. , Motoyoshi, H., Hachikubo, A., Sugiura, K., Yasunari, T. J., Eide, H., Storvold, R., Nakajima, Y., Takahashi, F.: In-situ measured spectral directional emissivity of snow and ice in the $8-14 \mu \mathrm{m}$ atmospheric window, Remote Sens. Environ., 100, 486-502, 2006.

Lamquin, N., Stubenrauch, C. J., and Pelon, J.: Upper tropospheric humidity and cirrus geometrical and optical thick- ness: Relationships inferred from 1 year of collocated AIRS and CALIPSO data, J. Geophys. Res., 113, D00A08, https://doi.org/10.1029/2008JD010012, 2008.

Lebsock, M. D., Stephens, G. L., and Kummerow, C.: An observed tropical oceanic radiative-convective cloud feedback, J. Climate, 23, 2065-2078, https://doi.org/10.1175/2009JCLI3091.1, 2010.

Liao, X., Rossow, W. B., and Rind, D.: Comparison between SAGE II and ISCCP high-level clouds, Part II: Locating cloud tops, J. Geophys. Res., 100, 1137-1147, 1995.

Liu, R., Liou, K.-N., Su, H., Gu, Y., Zhao, B., Jiang, J. H., and Liu, S. C. : High cloud variations with surface temperature from 2002 to 2015: Contributions to atmospheric radiative cooling rate and precipitation changes, J. Geophys. Res.-Atmos., 122, 54575471, doi :10.1002/2016JD026303, 2017.

Lloyd, J., Guilyardi, E., and Weller, H.: The Role of Atmosphere Feedbacks during ENSO in the CMIP3 Models. Part III: The Shortwave Flux Feedback, J. Climate, 25, 4275-4293, https://doi.org/10.1175/JCLI-D-11-00178.1, 2012.

Mace, G. G. and Zhang, Q.: The CloudSat radar-lidar geometrical profile product (RL-GeoProf): Updates, improvements, and selected results, J. Geophys. Res.-Atmos., 119, 9441-9462, https://doi.org/10.1002/2013JD021374, 2014.

Minnis, P., Sun-Mack, S., Young, D. F., Heck, P. W., Garber, D. P., Chen, Y., Spangenberg, D. A., Arduini, R. F., Trepte, Q. Z., Smith Jr., W. L., Ayers, J. K., Gibson, S. C., Miller, W. F., Chakrapani, V., Takano, Y., Liou, K.-N., Xie, Y., and P. Yang, Y.: CERES Edition-2 cloud property retrievals using TRMM VIRS and Terra and Aqua MODIS data, Part I: Algorithms, IEEE T. Geosci. Remote Sens., 49, 4374-4400, 2011.

Olsen, E. T., Kahn, B., Manning, E., Blaisdell, J., Iredell, L., and Susskind J.: AIRS/AMSU/HSB Version 6 Level 2 Quality Control and Error Estimation, Version 1.0, $30 \mathrm{pp}$, Jet Propulsion Laboratory, Pasadena, CA, available at: https: //docserver.gesdisc.eosdis.nasa.gov/repository/Mission/AIRS/ 3.3_ScienceDataProductDocumentation/3.3.5_ProductQuality/ V6_L2_Quality_Control_and_Error_Estimation.pdf, 2013.

Paul, M., Aires, F., Prigent, C., Trigo, I., and Bernardo, F.: An innovative physical scheme to retrieve simultaneously surface temperature and emissivities using high spectral infrared observations from IASI, J. Geophys. Res., 117, D11302, https://doi.org/10.1029/2011JD017296, 2012.

Protopapadaki, E.-S., Stubenrauch, C. J., and Feofilov, A. G.: Upper Tropospheric cloud Systems derived from IR Sounders: Properties of Cirrus Anvils in the Tropics, Atmosph. Chem. Phys., 17, 3845-3859, https://doi.org/10.5194/acp-17-3845-2017, 2017.

Reichler, T., Dameris, M., and Sausen, R.: Determining the tropopause height from gridded data, Geophys. Res. Lett., 30, 2042, https://doi.org/10.1029/2003GL018240, 2003.

Rossow, W. B. and Schiffer, R. A.: Advances in understanding clouds from ISCCP, B. Am. Meteorol. Soc., 80, 2261-2287, 1999.

Scott, N. A. and Chédin, A.: A fast line-by-line method for atmospheric absorption computations: the 4A Automized Atmospheric Absorption Atlas, J. Appl. Meteorol., 20, 801-812, 1981.

Seo, H., Subramanian, A. C., Miller, A. J., and Cavanaugh, N. R.: Coupled Impacts of the Diurnal Cycle of Sea Surface Temperature on the Madden-Julian Oscillation, J. Climate, 27, 84228443, https://doi.org/10.1175/JCLI-D-14-00141.1, 2014. 
Slingo, J. M. and Slingo, A.: The response of a general circulation model to cloud longwave radiative forcing. II: Further studies, Q. J. Roy. Meteor. Soc., 117, 333-364, 1991.

Smith, W. L., Knuteson, R. O., Revercomb, H. E., Feltz, W., Howell, H. B., Menzel, W. P., Nalli, N. R., Brown, O., Brown, J., Minnett, P., and McKeown, W.: Observations of the Infrared Radiative Properties of the Ocean-Implications for the Measurement of Sea Surface Temperature via Satellite Remote Sensing, B. Am. Meteorol. Soc., 77, 41-52, 1996.

Sohn, B.-J.: Cloud-Induced Infrared Radiative Heating and Its Implications for Large-Scale Tropical Circulations, J. Atmos. Sc., 56, 2657-2672, 1999.

Stephens, G. L., Vane, D. G, .Boain, R. J., Mace, G. G., Sassen, K., Wang, Z., Illingworth, A. J., O'Connor, E. J., Rossow, W. B., Durden, S. L., Miller, S. D., Austin, R. T., Benedetti, A., Mitrescu, C., and CloudSat Science Team: The CloudSat mission and the A-train, B. Am. Meteorol. Soc., 83, 1771-1790, 2002.

Stephens, G. L., O’Brien, D., Webster, P. J., Pilewski, P., Kato, S., and Li, J.-1.: The albedo of Earth, Rev. Geophys., 53, 141-163, https://doi.org/10.1002/2014RG000449, 2015.

Stephens, G. L., Hakuba, M. Z., Hawcroft, M., Haywood, J. M., Behrangi, A., Kay, J. E., and Webster, P. J.: The Curious Nature of the Hemispheric Symmetry of the Earth's Water and Energy Balances, Curr. Clim. Change Rep., 2, 135-147, https://doi.org/10.1007/s40641-016-0043-9, 2016.

Stubenrauch, C. J., Chédin, A., Armante, R., and Scott, N. A.: Clouds as Seen by Satellite Sounders (3I) and Imagers (ISCCP): II) A New Approach for Cloud Parameter Determination in the 3I Algorithms, J. Climate, 12, 2214-2223, 1999.

Stubenrauch C. J., Chédin, A., Rädel, G., Scott, N. A., and Serrar, S.: Cloud properties and their seasonal and diurnal variability from TOVS Path-B, J. Climate, 19, 5531-5553, 2006.

Stubenrauch, C. J., Cros, S., Lamquin, N., Armante, R., Chédin, A., Crevoisier, C., and Scott, N. A.: Cloud properties from AIRS and evaluation with CALIPSO, J. Geophys. Res., 113, D00A10, https://doi.org/10.1029/2008JD009928, 2008.

Stubenrauch, C. J., Cros, S., Guignard, A., and Lamquin, N.: A 6-year global cloud climatology from the Atmospheric InfraRed Sounder AIRS and a statistical analysis in synergy with CALIPSO and CloudSat, Atmos. Chem. Phys., 10, 7197-7214, https://doi.org/10.5194/acp-10-7197-2010, 2010.

Stubenrauch, C. J., Rossow, W. B., Kinne, S., Ackerman, S., Cesana, G., Chepfer, H., Di Girolamo, L., Getzewich, B., Guignard, A., Heidinger, A., Maddux, B., Menzel, P., Minnis, P., Pearl, C., Platnick, S., Poulsen, C., Riedi, J., Sun-Mack, S., Walther, A., Winker, D., Zeng, S., and Zhao, G.: Assessment of Global Cloud Datasets from Satellites: Project and Database initiated by the GEWEX Radiation Panel, B. Am. Meteorol. Soc., 94, 10311049, https://doi.org/10.1175/BAMS-D-12-00117.1, 2013.
Stubenrauch, C. J., Stephens, G. L., and UTCC PROES Team: Process Evaluation Study on Upper Tropospheric Clouds and Convection (UTCC PROES), GEWEX News, 27, 46, available at: http://www.gewex.org/gewex-content/files_mf/ 1500657263May2017.pdf (last access: November 2017), 2017.

Susskind, J., Barnet, C., and Blaisdell, J.: Retrieval of atmospheric and surface parameters from AIRS/AMSU/HSB data in the presence of clouds, IEEE T. Geosci. Remote Sens., 41, 390-409, 2003.

Susskind, J., Blaisdell, J., and Iredell, L.: Improved methodology for surface and atmospheric soundings, error estimates, and quality control procedures: the atmospheric infrared sounder science team version-6 retrieval algorithm, J. Appl. Remote Sens., 8, 084994, https://doi.org/10.1117/1.JRS.8.084994, 2014.

Trigo, I. F., Boussetta, S., Viterbo, P., Balsamo, G., Beljaars, A., and Sandu, I.: Comparison of model land skin temperature with remotely sensed estimates and assessment of surfaceatmosphere coupling, J. Geophys. Res.-Atmos., 120, 1209612111, https://doi.org/10.1002/2015JD023812, 2015.

Van T. Dang, H., Lambrigtsen, B., and Manning, E.: AIRS/AMSU/HSB Version 6 Level 2 Performance and Test Report, Version 1.2, 197 pp., Jet Propulsion Laboratory, available at: https://disc.sci.gsfc.nasa.gov/AIRS/documentation/v6_docs/ v6releasedocs1/V6_L2_Performance_and_Test_Report.pdf, 2012.

Webster, P. J., Clayson, C. A., and Curry, J. A.: Clouds, Radiation, and the Diurnal Cycle of Sea Surface Temperature in the Tropical Western Pacific, J. Climate, 9, 1712-1730, 1996.

Winker, D., Getzewitch, B., and Vaughan, M.: Evaluation and Applications of Cloud Climatologies from CALIOP, Proc. Int. Laser Radar Conference (ILRC), 23-27 June 2008, Boulder, USA, 4 pp., 2008.

Winker, D. M., Vaughan, M. A., Omar, A., Hu, Y., and Powell, K. A.: Overview of the CALIPSO mission and CALIOP data processing algorithms, J. Atmos. Ocean. Techn., 26, 2310-2323, 2009.

$\mathrm{Wu}, \mathrm{X}$. and Smith, W. L.: Emissivity of rough sea surface for 8 $13 \mu \mathrm{m}$ : modelling and verification, Appl. Optics, 36, 2609-2619, 1997.

Zhou, C., Zelinka, M. D., Dessler, A. E., and Yang, P.: An analysis of the short-term cloud feedback using MODIS data, J. Climate, 26, 4803-4815, https://doi.org/10.1175/jcli-d-12-00547.1, 2013.

Zhou, C., Zelinka, M. D., Dessler, A. E., and Klein, S. A.: The relationship between interannual and long-term cloud feedbacks, Geophys. Res. Lett., 42, 10463-10469, https://doi.org/10.1002/2015GL066698, 2015. 